\title{
UNDERSTANDING RESEARCH AND ETHICS
}

Stephen V. Flynn and Tynisha I. Ingerson

\section{LEARNING OBJECTIVES}

After reading this chapter, you will be able to:

- Define the scientist practitioner model

- Recognize the philosophical integration of qualitative and quantitative research

- Explain research rigor

- Recognize the nuances of research identity

- Describe basic research ethics

\section{INTRODUCTION TO RESEARCH AND ETHICS IN THE BEHAVIORAL SCIENCES}

This chapter is your introduction to social science research and ethical considerations. Early-, mid-, and late-career professionals entering the world of research will likely be surprised by the number of research traditions, methods, and procedures available to them. Because very few textbooks introduce a wide-ranging collection of research methodology, many helping professionals feel ill equipped to understand what approach they want to utilize and how to effectively execute the associated methods. To further confuse adult learners, much of the literature in the behavioral sciences fails to adequately match pragmatic aspects of a research tradition (methods, sampling procedures, trustworthiness procedures) with the overarching research philosophy (ontology, epistemology, theory).

\section{RESEARCH TRADITIONS}

This textbook aims to provide a sophisticated overview of 17 unique research traditions and an introduction to the worlds of research ethics, research writing, statistics, and the history of research in the social sciences. Within each chapter, the author(s) provide a concise 
breakdown of the research tradition's philosophical integration. This philosophical hierarchy encompasses five levels: ontology (i.e., form and nature of reality), epistemology (i.e., theory of knowledge acquisition), theoretical stance (i.e., philosophical stance), methodology (i.e., process for discovering what is knowable), and method (i.e., procedures for gathering and analyzing data (Flynn \& Korcuska, 2018a,b; Flynn, Korcuska, Brady, \& Hays, 2019). By perusing chapters that outline a coherent methodological blueprint, emerging and seasoned researchers alike can glean an in-depth understanding of the various paradigmatic levels of a research tradition and how these levels inform one another. In other words, a research tradition's philosophical descriptions will demonstrate how your decision to use a particular methodology or method is linked to the manner in which you view reality. In exploring these vantage points, you will have an opportunity to fully consider a research tradition's theoretical blueprints.

In addition to laying out the coherent blueprints of 17 unique research traditions, every chapter will teach you how to increase the rigor of a particular research tradition. Methodological rigor can be determined by the degree to which a researcher uses a systematic and coherent approach in designing a study that exemplifies validity, trustworthiness, diversity, and amount of data collected (Flynn et al., 2019; Kline, 2008). Researchers and reviewers of research place great importance on a study's rigor because it partly determines the nature and the meaning of the findings. Given the unique standards within each research tradition, rigor will not always look the same. For example, using one subject for a survey research project would not be considered rigorous, yet it would be considered normative in case study research.

\section{ACCREDITATION AND IDENTITY DEVELOPMENT}

Throughout this textbook, accreditation standards are considered in the context of research design. Accredited institutions are required to meet acceptable levels of quality in research training. Graduate programs accredited through national organizations such as the Council for Accreditation of Counseling and Related Education Programs (CACREP), the American Psychological Association (APA), the Commission on Accreditation for Marriage and Family Therapy Education (COAMFTE), and the Council on Social Work Education (CSWE) emphasize research considerations in the training of mental health practitioners. Accredited programs engage in a continuous review process to meet and maintain research standards, ethics, faculty identity, curriculum, and licensure expectations set by the profession (Black \& Flynn, 2020).

It would be an understatement to describe identity development as a major movement in the counseling profession. In fact, counselor education training programs have been tasked with developing a professional counselor identity within trainees (CACREP, 2016; Gibson, Dollarhide, \& Moss, 2013) and scholars have described counselor identity development as a national imperative (Spurgeon, 2012). In addition to facilitating overall identity development, training programs have been charged with creating a research culture and identity (Lambie \& Vaccaro, 2011). Over the past 15 years, there has been scholarly discourse about other forms of identity in relation to research, including methodological research identity (Flynn et al., 2019), qualitative research identity (Reisetter et al., 2004), counselor education doctoral student research identity (Lamar \& Helm, 2017), and master's level counselor research identity (Jorgensen \& Duncan, 2015). Given this emphasis on identity, together with the particular applicability of various traditions, this textbook will illuminate certain aspects of the methodological identity of each research tradition 
through careful articulation of ontology, epistemology, theory, methods, sample size, participant populations, standards of rigor, and multicultural considerations.

\section{RESEARCH ETHICS}

Research ethics aims to promote the rights and welfare of participants while pursuing our shared interest in enhancing the world through investigations that fall in line with ethical principles and federal regulations. Most individuals who are completing advanced research courses or going through their university's ethics training program (e.g., Collaborative Institutional Training Initiative [CITI]) as part of the institutional review board (IRB) expectations, will review grievously unethical experiments such as the Tuskegee Syphilis Study, Jewish Chronic Disease Hospital Cancer Cell Injections, Willowbrook Study, and NAZI Medical War Crimes (National Institutes of Health $[\mathrm{NIH}], 2002)$. The aforementioned research-based atrocities are important to review for a number of reasons (e.g., to avoid repeating history, to better understand the parameters of ethical research). In addition to repudiating unethical experiments such as these, mid-20th century scholars focused their efforts on creating systems, such as the Belmont Report Principles, that protect human participants from harm.

The importance of protecting research participants in the social sciences is balanced with the need to provide behavioral science scholars with the academic freedom to explore topics that create dissent (Whitney, 2016). Topics sensitive to public opinion such as sexuality, racial discrimination, and participant perception on a variety of constructs (e.g., financial compensation disparities, gun control, homicidal ideation), are most often explored within social science research. With the appropriate procedures in place (e.g., protection of vulnerable populations, informed consent, full disclosure of procedures, assent, opt out), potential subjects can explore such topics with little risk of uninformed psychological, social, physical, cognitive, and/or moral injury. Although some of these topics may be sensitive territory for participants, institutions, and those holding particular political vantage points, researchers have the right to ground contemporary political topics in scholarly evidence. According to the Electronic Code of Federal Regulations (2018), "The IRB should not consider possible long-range effects of applying knowledge gained in the research (e.g., the possible effects of the research on public policy) as among those research risks that fall within the purview of its responsibility" (45 CFR 46.111(a)(2)) (https://www.ecfr.gov/cgi-bin/retrieveECFR?gp=\&SID= 83cd09e1c0f5c6937cd9d7513160fc3f\&pitd=20180719\&n=pt45.1.46\&r=PART\&ty=HTML).

Some behavioral science practitioners, particularly those who have little interest in conducting research, might ask themselves, "How do research ethics apply to clinical work?" In response to this common question, it is indisputable that clinicians have an ethical imperative to engage in evidenced-based practice (American Counseling Association [ACA], 2014; CACREP, 2016). According to Wester and Hines (2017), evaluating client progress and counselor effectiveness is a method for engaging in evidence-based practice. Analyzing data from symptom checklists, outcome questionnaires, surveys, and inventories at various points in treatment (each session, 3 weeks, 1 month, 3 months) is effective for gathering data on client progress and determining whether a client is ready for the next stage of treatment (e.g., termination). For example, the Outcome Questionnaire 45.2, the most peer-reviewed self-report outcome measure in the world, measures client symptomology on three subscales: symptom distress, interpersonal relations, and social role. These scales, along with various critical items measuring suicidal ideation, violence, 
and substance abuse, provide clinicians with frequent snapshots of how clients are functioning across a variety of domains. By analyzing changes in the data, clinicians can measure the effects of their interventions along with the symptom disposition of their clients (Lambert et al., 2004).

\section{THE SCIENTIST-PRACTITIONER MODEL}

With the increasing demand for evidence-based treatments, the scientist-practitioner (SP) model (also known as the "Boulder model") is gaining increased attention for its emphasis on the personal experiences of clinicians and researchers (Sheperis, 2017). This clinical emphasis leads to more effective treatment and is considered best practice within the behavioral sciences. Outlined in 1949, the SP model is based on the belief that trained professional mental health workers (psychologists, counselors, therapists, etc.) should be well versed in both clinical practice and human subjects research (Jones \& Mehr, 2007). The SP model is the most widely used training model for graduate students in the behavioral sciences. While the SP model was initially intended for use within clinical psychology, its efficacy extends to training other helping professionals (e.g., counselors, social workers, marriage and family therapists) as well (Sheperis, 2017). The model stresses the importance of developing strong evaluative skills, and clinical researchers are directed to explore topics that are meaningful and relevant to their practice (Alderman \& Knight, 2017).

The SP model has provisions that help a therapist ensure that their own biases and opinions are not influencing their practice. It is easy to envision how practitioners might impose their own biases in their work with clients. Simply having a preferred treatment method can be an example of bias. This preference becomes problematic if the practitioner does not have evidence to support the efficacy of the method. For example, it would likely be considered inappropriate and unethical for a therapist to decide to make Eye Movement Desensitization and Reprocessing (EMDR) the primary mode of treatment for a client who has been diagnosed with anorexia nervosa. Perhaps the clinician's thinking is centered on the success they had when conducting EMDR with a client who had been diagnosed with posttraumatic stress disorder (PTSD). The SP model postulates that the therapist must research the efficacy of EMDR for clients diagnosed with anorexia nervosa before implementing the intervention with such clients.

According to Lowman (2012), the SP model requires practitioners to explain to their clients the rationale for a treatment's efficacy. This rationale is often based on the knowledge the clinician has gained from their own review of research, rather than their personal opinion. The importance of knowledge and concern for efficacy, limitations, and liabilities are to be stressed by SPs (Lowman, 2012). Furthermore, the SP model helps to connect diverse therapeutic professions with the promotion of research in clinical practice. The SP model incorporates three parts, together with three assumptions. The three parts assigned to clinicians include becoming producers of new data, engaging in the review of relevant research, and becoming evaluators of effective therapy (Sheperis, 2017). Engaging in the dual roles of practitioner and scientist produces clinicians who are involved in the research process as well as researchers who are more involved in clinical work (Crane \& Hafen, 2002). The three assumptions within the SP model include (but are not limited to) the following: (a) clinicians, with an understanding of research methods, will promote effective psychological services; (b) research is crucial to the advancement of scientific databases; and (c) the direct involvement of researchers in therapeutic practice facilitates accurate understanding and treatment of crucial social issues (Jones \& Mehr, 2007). 


\section{COHERENTLY NESTING RESEARCH METHODS}

Throughout this textbook we will label various research paradigms in several ways, including nesting, paradigmatic hierarchy, and philosophical integration. At this point you may be asking, "Why is this information important to understand?" First, it is important to realize that research traditions go beyond qualitative, quantitative, and mixed methods descriptions. Researchers and reviewers of research acknowledge that understanding and showcasing the ontological, epistemological, theoretical, and methodological issues and constructs associated with a research project (a) constitutes a comprehensive analysis of the research process; and (b) justifies the use of specific methods. Understanding the philosophical integration of a research process helps scholars in three additional ways. First, it helps them understand the theoretical assumptions behind their work (e.g., grounded theory's use of inductive reasoning, intersubjectivity of ethnography). Second, it can ensure the accuracy of their research (e.g., statistical analysis standards used in survey research). Third, it provides a unique interpretation of the data. In other words, the knowledge gained by applying various methodological frameworks will differ based on the distinctive assumptions embedded within the philosophical integration (e.g., positivism's accurate and unambiguous interpretation of the world; Crotty, 2003).

\section{QUALITATIVE, QUANTITATIVE, AND MIXED METHODS}

To start, we explore definitions of qualitative, quantitative, and mixed methods research. In describing these constructs, it is important that you, the reader, understand that these terms focus on how a researcher approaches data and methods. In other words, while general terms are often used to describe data, these terms alone do not acknowledge that the knowledge produced and interpreted through various methodological frameworks differs based on the integration of ontology, epistemology, and theoretical assumptions (Crotty, 2003). We understand that much of the literature, in various fields, describes these terms as being synonymous with research paradigms (i.e., ontology, epistemology, theoretical stance, methodology, and methods), however, as you have already surmised, the research world extends far beyond a singular worldview such as this (Shannon-Baker, 2016). While it is important to understand why a researcher might choose a particular methodology, these general terms also provide a quick way to ascertain how a researcher is approaching the data that are collected. In addition, due to the proliferation of these terms in the research literature, it is important for all researchers to understand their meaning.

You may also be wondering why qualitative, quantitative, and mixed methods research need separate terms and procedures for ensuring that a study has merit and rigor. For starters, quantitative researchers use the scientific method (i.e., replicability, precision, falsifiability, and parsimony) to investigate research questions. Unlike qualitative research, quantitative studies rely on probability theory. For example, researchers who employ quantitative methodology often use a type of sampling that is based on theories of probability, called probability sampling (e.g., random sampling, stratified sampling, cluster sampling). A probability sampling method is any method of sampling that utilizes some form of random selection of participants. In order to employ a random selection method, you must set up a process or procedure that ensures that different aspects of your population have equal probability of being chosen. When conducting quantitative research, researchers utilize the scientific method to collect measurable statistical evidence in a hypothesized experiment, with the results ultimately supporting or failing to support a theory (Bhattacherjee, 2012). 
In comparison, qualitative researchers engage in nonprobability sampling because they are not interested in generalizing their findings to a larger population, and consequently, participants are not selected according to the logic of probability. Qualitative researchers reject the notion that randomized samples equate to truth. Participants are selected because they meet a particular criterion or because of participant convenience and access. A major goal of qualitative research is to purposefully explore in-depth experiences of a specific group, family, or individual in a naturalistic context. As such, qualitative researchers reject the notion that randomized events relate to social life (Merriam, 1998).

The number of qualitative research articles published within counseling and related journals has increased significantly over the past two decades (Arredondo, Rosen, Rice, Perez, \& TovarGamero, 2005; Woo \& Heo, 2013). This textbook provides an in-depth introduction to five unique qualitative research traditions: case study research, phenomenological research, grounded theory research, narrative research, and consensual qualitative research. In addition, a section within the content analysis chapter covers qualitative content analysis. According to Punch (1998), qualitative research includes traditions that collect and analyze data that are not in the form of numbers. A second, more detailed, definition states that "Qualitative research is multimethod in focus, involving an interpretive, naturalistic approach to its subject matter. This means that qualitative researchers study things in their natural settings, attempting to make sense of, or interpret, phenomena in terms of the meanings people bring to them" (Denzin \& Lincoln, 2000, p. 3).

Quantitative research statistically uncovers patterns that are meant to generalize to a larger population. Quantitative researchers gather numerical data to categorize, rank order, and analyze their findings. These patterns, together with associated raw data, are often visually displayed in graphs and tables (McLeod, 2013). This textbook offers an in-depth review of five unique quantitative designs: survey research, experimental research, predictive research, content analysis research, and single-subject design research. In addition to these distinct approaches, Chapter 4 provides an overview of descriptive, inferential, and Bayesian statistics.

According to Johnson, Onwuegbuzie, and Turner (2007), mixed methods research is a type of methodology in which a researcher combines elements of qualitative and quantitative research to achieve breadth and depth of understanding and corroboration of the findings. Similar to other research traditions, mixed methods research has philosophical assumptions and tenets that guide researchers in deciding how and when certain data are collected and in what manner results are interpreted. Within this textbook, you will explore the world of mixed methods research in four chapters covering seven unique methodological frameworks: action research, convergent (triangulation) design research, embedded design research, explanatory design research, exploratory design research, transformative design research, and multiphase design research.

Throughout the past 20 years there has been significant growth in the mixed methods literature. Due to the proliferation of this innovative approach, mixed methods has beenlabeled the third methodological movement (following qualitative and quantitative research; Tashakkorie \& Teddlie, 2010). Mixed methods research is a process that uses unique configurations of qualitative and quantitative threads and points of interface (i.e., synthesis of qualitative and quantitative information) to create new data and knowledge. This process of cohesively integrating both qualitative and quantitative processes and data is known as commensurability legitimation. During the commensurability legitimation process mixed methods researchers explore unique thread configurations, including exploratory (i.e., larger initial qualitative thread smaller secondary quantitative thread), explanatory (i.e., larger initial quantitative thread smaller secondary qualitative thread), convergent (i.e., simultaneous use of full qualitative and quantitative threads), and embedded (i.e., main thread and an embedded secondary thread) and multiple sequences (e.g., concurrent, sequential, and single phase). Next, 
mixed methods researchers focus on integrating threads at various point-of-interface (e.g., sampling, data collection, data analysis, conclusion) and the eventual creation of meta-inferences (i.e., integrated qualitative and quantitative results). While the new meta-inferences produced by the mixing of methods are important, mixed methods researchers also ensure the valid and trustworthy application of the separate qualitative and quantitative threads prior to the mixing process (i.e., multiple validities legitimation; Onwuegbuzie \& Johnson, 2006).

Since the split between qualitative and quantitative research is primarily at the data level, the most accurate way to discuss philosophical integration is to refer to the epistemological split between constructionism/subjectivism and objectivism. Most qualitative research has either a constructionist or subjectivist epistemological approach. Similarly, most quantitative research has an objectivist epistemology. Sound research requires the researcher to determine an appropriate philosophical integration that warrants merit in the eyes of observers. Most researchers do not embark on a project with their overarching philosophical integration already in place. Instead, they begin with a question or a series of questions they would like to answer. After identifying these questions, it is the researcher's responsibility to create a process through which to answer the questions. The process should include ontology, epistemology, theoretical stance, methodology, and methods (Crotty, 2003). In addition, while the philosophical integration is recommended for most qualitative and quantitative approaches, many mixed methods approaches direct scholars to nest their methodology and methods within the paradigm of pragmatism (Hanson, Plano-Clark, Petska, Creswell, \& Creswell, 2005) or to meet the philosophical integration expectations of both qualitative and quantitative approaches within a singular investigation.

\section{RESEARCH PROBLEMS AND QUESTIONS}

Selecting your research problem will be the first step in your research process and is one of the most important (Salkind, 2010). The research problem is the topic that the researcher intends to investigate, and it is usually a concern or issue that the researcher wants to explore. When selecting the research problem, investigators will review literature related to the topic and consult with peers in the field (Sheperis, 2017). This preliminary work is done in hopes of finding a gap in the literature and undertaking research that will help to narrow the scope of the research problem. The research problem starts with a concept that, through investigation, discussion, and refinement, becomes the research problem. An example of a research problem in the behavioral sciences could be the following: There are moral and ethical implications involved in the treatment of refugee families who are separated and detained at the southern border of the United States.

Following the identification of the research problem, the research question will begin to form. The research question is used to guide an investigation and pursue philosophical integration, and it is a fundamental step toward creating a viable research plan. Examples of research questions include the following: "Does frequency of exercise, for incarcerated males, influence their participation in support groups?" or "How does the carbohydrate intake of school-aged children with a diagnosis of attention deficit/hyperactivity disorder impact the child's ability to pay attention during homework time?"

\section{Utilizing Resources to Explore Possible Research Problem(s) and Question(s)}

To identify the research problem and create the research question, researchers consult with colleagues and review existing literature related to the topic. Reviewing previous research provides 
a better understanding of related subject matter and previous research. It also helps the researcher identify potential gaps in the research. From here, the researcher develops a clearer understanding of the research problem and begins to formulate the research question. It is not uncommon for researchers to write a short section at the end of their article explaining how their research could be taken a step further or even describe additional research questions that emerged during the project.

\section{Narrowing and Clarifying the Research Problem and Question}

Three steps help the researcher to narrow and clarify the research question (Geher, 2019). Step one involves creating the research question from a theoretical perspective. Step two requires the researcher to magnify variables. Step three takes place as the researcher operationally defines each of the variables identified in step two.

\section{Variations of Research Questions}

Below are eight variations of research questions. To decide which type will best suit your project, it is necessary to first understand the unique attributes of each variation (Meltzoff \& Cooper, 2018).

- Existence questions involve observing whether something exists or occurs. For example, can signs of dementia be detected in MRI brain scans?

- Description and classification questions ask what characteristics something has. For example, what are the most common personality traits of a stay-at-home father?

- Composition questions ask what something consists of. For example, what factors are considered when preparing to teach a special needs class?

- Descriptive-comparative questions compare group X to group Y. For example, are single mothers or single fathers more likely to be seeking a romantic partner?

- Relationship questions ask whether there is a relationship between $\mathrm{X}$ and Y. For example, do commute times affect job performance?

- Causal questions ask whether X changes, halts change, or creates Y. For example, does father involvement affect a female child's self-esteem?

- Causal-comparative questions compare the level of change that $\mathrm{Y}$ and $\mathrm{Z}$ evoke in $\mathrm{X}$. For example, are male or female teachers more effective in defusing potential conflict among high school students?

- Causal-comparative interactional questions seek to determine whether X evokes more change in $\mathrm{Y}$ than $\mathrm{Z}$ does, given certain circumstances. For example, do the daughters of stay-athome fathers have more secure self-esteem than the daughters of stay-at-home mothers?

\section{METHODOLOGICAL RESEARCH QUESTION}

You may understand that your research question will guide your investigation and your philosophical integration, yet you may be asking yourself, "How do I know whether I am asking a qualitative, qualitative, or mixed methods research question?" Qualitatively, you are usually starting with an open-ended question beginning with the words "what" or "how." Next, you would present the phenomenon being explored. In addition to the central question under investigation, 
sub-questions are often utilized to further analyze the construct. Qualitative research questions often avoid using the word "why" or setting up a direct comparison. For example, qualitative researchers avoid questions with certain verbs, such as "relate," "influence," "affect," or "cause." Questions of this ilk often describe a direct comparison or a cause-and-effect relationship and are more in line with quantitative investigations (Hurlburt, 2017).

Quantitative research questions contain an independent variable $(x$; i.e., a characteristic that is changed or controlled) and a dependent variable $(y)$ or variables (i.e., outcomes that occur when the independent variable changes). The researcher measures, manipulates, and controls variables to look for descriptions, relationships, and/or comparisons. The overarching research question, in quantitative research, typically starts with words like "how," "what," or "why." Similarly, quantitative hypotheses, which are tested statistically, are guesses the researcher makes about the probable associations among variables. Quantitative researchers have something specific they are attempting to research and are careful to keep the research clear and focused by not asking participants openended questions (Sheperis, Young, \& Daniels, 2017).

Researchers who are looking to create a study that has both qualitative and quantitative dimensions will likely be using a mixed methods approach. The research question style and format should match the nature of the questions. The overarching mixed methods approach will guide the researcher on how to create the research questions. For example, certain mixed methods investigations (e.g., explanatory research design) have a large quantitative thread and small qualitative thread, while other traditions (e.g., exploratory research design) have a major qualitative thread and minor quantitative thread. The research questions should fully incorporate the threads the researcher is aiming to uncover and should also address the mixing of threads (Creswell \& Plano Clark, 2017).

\section{THE PURPOSE STATEMENT}

During the process of developing your research problem and researcher questions, you have been consciously or unconsciously developing your purpose statement. Alternatively, you may have developed your purpose statement prior to developing your research questions. According to Hays and Singh (2012), "The point of a purpose statement is to anchor the proposal or study; it is where the conceptual framework and research design meet" (p. 127). Researchers use a declarative purpose statement to capture the main goals of their project. The purpose statement is different from the action-oriented research questions and should stimulate the readers' interest in the overall topic. On the other hand, it is similar to a research question because the purpose needs to be very specific and detailed. A benefit of creating a well-crafted purpose statement is that, in writing the statement, you will simultaneously enhance, clarify, and formulate your research questions.

While variability exists, the research purpose statement is often placed at the beginning of the methodology section of the manuscript or at the end of the manuscript's literature review section. There are some common steps to keep in mind when developing your purpose statement. First, the researcher(s) engaging in the project must be reasonably certain that no major investigations have already fulfilled the stated purpose. For this step to be successful, it is essential for the researchers to be well versed in the relevant research and literature on the topic. Second, the purpose of any research study should relate directly to the previously identified research problem. Third, researchers should be clear and concise regarding what they are investigating while avoiding stating any potential outcomes. Lastly, the purpose statement should inform the reader if the investigation is qualitative, quantitative, or mixed methods in nature (Hays \& Singh, 2012). 
Whether you are using a qualitative, quantitative, or mixed methods tradition there are certain tradition-specific issues to keep in mind. There are certain factors that you must consider when creating a qualitative purpose statement. Haverkamp and Young (2007) described the essence of the purpose statements of specific qualitative research traditions. For example, a grounded theory purpose statement is centered on exploring underlying processes while a phenomenological purpose statement is aimed at describing the lived experience of a construct. Similarly, quantitative researchers provide the reader information on their procedures within the purpose statement. For example, if researchers plan to test a theory, it would be stated in very clearly within the purpose statement along with the independent and dependent variables. Shoonenboom and Johnson (2017) described a common purpose for incorporating any mixed methods framework: to expand, strengthen, and corroborate the analysis and results of an investigation with complementary qualitative and quantitative threads. Similar to qualitative and quantitative traditions, specific mixed methods design (e.g., embedded, convergent, exploratory, explanatory, transformative, multiphase) have their own specific purpose requirements. Greene, Caracelli, and Graham (1989) described five common purposes for mixing methods, including triangulation, complementarity, development, initiation, and expansion (see Chapter 17 for a review of these factors).

\section{OVERVIEW OF PHILOSOPHICAL INTEGRATION IN RESEARCH}

Scholars refer to the philosophical integration of a research tradition as a paradigm. Paradigms, or world views, are a series of constructed entities about how problems should be considered and addressed (Kuhn, 1962). It is important for you to know that there is a tremendous amount of literature in the scholarly and philosophical worlds about the notion of a research paradigm and nuances of a paradigm; however, this book will provide an introduction to the most common elements of a paradigm. These elements include serving as a theoretical umbrella for unique configurations of ontology, epistemology, theory, methodology, and methods. Figure 1.1 displays the nature of a research paradigm. The double-sided arrow under the word paradigm indicates that the paradigm encompasses this unique philosophical integration. The philosophical integration itself (i.e., ontology, epistemology, theoretical stance, methodology, and methods) is hierarchical, yet the arrows indicate interaction on every level. Finally, the combination of unique philosophical and pragmatic aspects of a research project interact with the original research problem, research question(s), and purpose statement.

Ontology is the study of being. The ontological perspective in social science research essentially involves trying to answer the question "What is the nature of existence?" Within a research tradition's philosophical integration, there exists a particular manner in which the approach acknowledges the nature of being. While there are quite a few ontological positions in philosophy (see Effingham, 2013), two common research-based ontological positions include realism (i.e., some positivist and objectivist positions) and relativism (i.e., some constructionist and postmodern positions). The ontological position of realism is the view that objects exist outside of being perceived (Phillips, 1987). Authors suggest that realism has been the leading ontological view in social science research (Maxwell, 2008). According to Guba and Lincoln (1994), a research methodology promoting a relativist ontology postulates a finite number of subjective experiences of a phenomenon. From a relativistic perspective, reality cannot be distinguished from one's subjective experience.

Epistemology informs us of the nature of knowledge. It asks the question, "How do you know something?" (Crotty, 2003). In the context of a research paradigm, epistemology informs the 


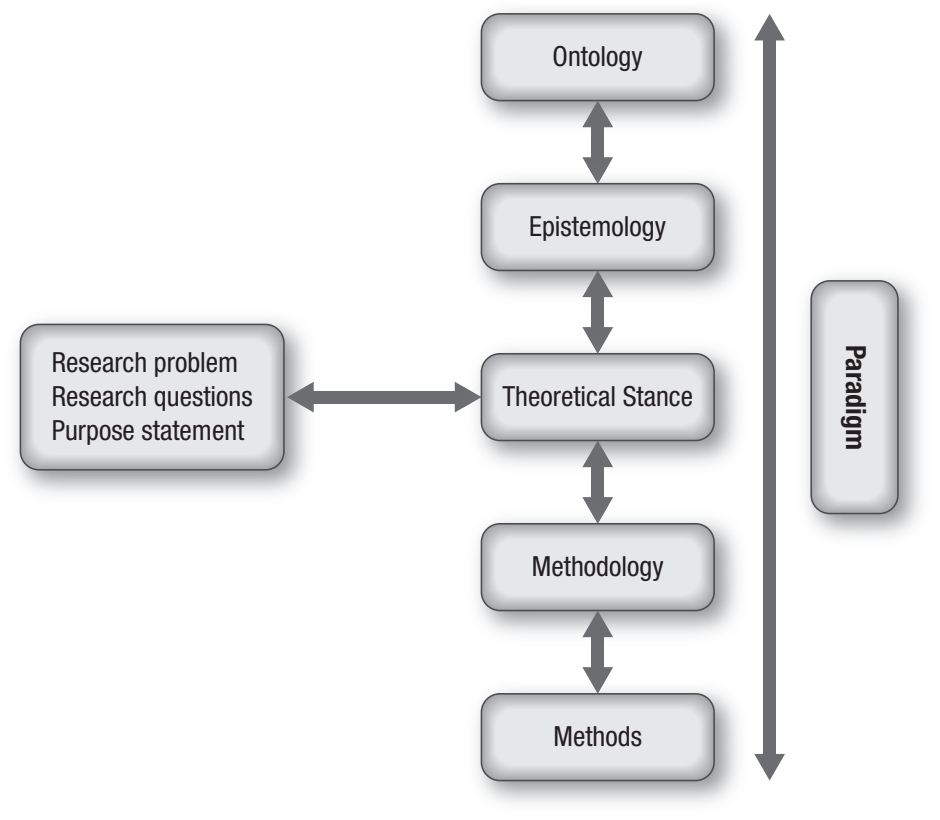

FIGURE 1.1 The Nature of a Research Paradigm in Behavioral Science Research.

NOTE: Double-ended arrows = interaction; large vertical double-ended arrow underneath the word paradigm demonstrates that the paradigm encompasses ontology, epistemology, theoretical stance, methodology, and methods.

theoretical perspective through apprising a researcher on what kind of knowledge is possible and legitimate (Maynard, 1994). Similar to philosophical ontology positions, there are many philosophical epistemologies (see Audi, 2010). Common epistemologies used in social science research include objectivism, constructionism, and subjectivism. From an objectivist vantage point, knowledge exists apart from any conscious individual or group meaning construction. Things have an intrinsic meaning outside of subjective or collective thought. Constructionism implies that knowledge is constructed through the interaction of realities. Various individuals and groups can construct knowledge in different ways and the interaction of these knowledges can create meaning. The subjectivist vantage point postulates that knowledge about a construct is created subjectively by an individual. Whether it is through introspection, a dream, or a passing thought, knowledge is created within the individual and placed on the object of study.

A research theoretical perspective is a series of assumptions that inform the research methodology and process. The theoretical perspective is essentially a philosophical stance that answers the question, "What theoretical perspective lies behind the methodological framework?" (Crotty, 2003). Two common theoretical frameworks include positivism and critical inquiry. Positivism is a theoretical position that posits information taken from sensory experiences, filtered through logic, and creates knowledge. An assumption of this approach is that truth is only discovered through experience and empirical knowledge (Johnson, 2014). In comparison, the assumptions grounded in critical inquiry include the inherent connection between values, knowledge, and politics. This vantage point assumes that truth emerges through speech and discussion (Fui, Khin, Khin, \& Ying, 2011). Table 1.1 provides a cohesive overview of the major research-based theoretical perspectives, a selected theoretical pioneer, influencing epistemology, and snapshot of the theory's view on 
TABLE 1.1 Theoretical Perspectives and Associated Pioneers, Epistemologies, and Views on Reality

\begin{tabular}{|c|c|c|c|}
\hline THEORY & EARLY PIONEER & EPISTEMOLOGY & REALITY IS BASED ON \\
\hline Positivism & $\begin{array}{l}\text { Auguste Comte } \\
(1798-1857)\end{array}$ & Objectivism & $\begin{array}{l}\text { Positivists believe reality is based on } \\
\text { what is observed scientifically through } \\
\text { empirical methods. Positivists believe } \\
\text { everything can be explained using the } \\
\text { scientific method. }\end{array}$ \\
\hline Post-Positivism & $\begin{array}{l}\text { Sir Karl Popper } \\
\text { (1902-1994) }\end{array}$ & Objectivism & $\begin{array}{l}\text { Post-positivists believe reality is based } \\
\text { on what is observed scientifically; } \\
\text { however, post-positivists acknowledge } \\
\text { that the researcher can influence the } \\
\text { observed object. }\end{array}$ \\
\hline Interpretivism & $\begin{array}{l}\text { Max Weber } \\
\text { (1864-1920) }\end{array}$ & Constructionism & $\begin{array}{l}\text { Interpretivists believe there are } \\
\text { multiple realities due to different } \\
\text { perceptions. Meaning is derived from } \\
\text { one's view of reality. }\end{array}$ \\
\hline $\begin{array}{l}\text { Symbolic } \\
\text { Interactionism }\end{array}$ & $\begin{array}{l}\text { George H. Mead } \\
(1863-1931)\end{array}$ & Constructionism & $\begin{array}{l}\text { Symbolic interactionists believe reality } \\
\text { is made comprehendible through } \\
\text { human interaction with symbols and } \\
\text { language. }\end{array}$ \\
\hline Constructivism & $\begin{array}{l}\text { John Dewey } \\
\text { (1933-1998) }\end{array}$ & Constructionism & $\begin{array}{l}\text { Constructivists believe individuals } \\
\text { construct their own understandings } \\
\text { through the interaction of what they } \\
\text { already know and the ideas with which } \\
\text { they come into contact. }\end{array}$ \\
\hline Critical Inquiry & \begin{tabular}{|l} 
Karl Marx \\
(1818-1883)
\end{tabular} & Subjectivism & $\begin{array}{l}\text { Critical Inquiry views reality as shaped } \\
\text { by social, political, cultural, economic, } \\
\text { ethnic, and gender values formed over } \\
\text { time in individuals' lives. }\end{array}$ \\
\hline Phenomenology & $\begin{array}{l}\text { Edmund Husserl } \\
(1859-1938)\end{array}$ & Subjectivism & $\begin{array}{l}\text { Phenomenological reality is shaped } \\
\text { through individual's lived experiences } \\
\text { within the world. }\end{array}$ \\
\hline Feminism & $\begin{array}{l}\text { Elizabeth C. } \\
\text { Stanton } \\
(1815-1902)\end{array}$ & Subjectivism & $\begin{array}{l}\text { Feminist reality is based on lived } \\
\text { experiences and the belief in human } \\
\text { equality, and that old systems of } \\
\text { oppression must change. }\end{array}$ \\
\hline Post-Modernism & $\begin{array}{l}\text { Jacques Derrida } \\
\text { (1930-2004) }\end{array}$ & Subjectivism & $\begin{array}{l}\text { Objectivity and reality are individually } \\
\text { or socially constructed, everything is } \\
\text { perspective, there is no such thing as } \\
\text { objective fact. }\end{array}$ \\
\hline
\end{tabular}

NOTE: Each theory has multiple pioneers, however, only one is listed; Given a research configuration, the influencing epistemology could change.

reality (Crotty, 2003). Chapter 2 provides a more thorough review of relevant behavioral science research theories and theorists.

Methodology provides a plan and procedure for discovering new knowledge. This level of nesting also provides the blueprints for what methods might be used to uncover the information. Methodology is a more pragmatic aspect of the paradigm that answers the question, "What methodology governs the choice in methods?" (Crotty, 2003). Examples of methodological frameworks include survey research and phenomenological research. These along with 11 
TABLE 1.2 The Components of a Paradigm

\begin{tabular}{|l|l|l|l|l|}
\hline ONTOLOGY & EPISTEMOLOGY & $\begin{array}{l}\text { THEORETICAL } \\
\text { STANCE }\end{array}$ & METHODOLOGY & METHODS \\
\hline $\begin{array}{l}\text { What is the } \\
\text { nature of } \\
\text { existence? }\end{array}$ & $\begin{array}{l}\text { How do we know } \\
\text { something? }\end{array}$ & $\begin{array}{l}\text { What theory } \\
\text { lies behind the } \\
\text { methodological } \\
\text { framework? }\end{array}$ & $\begin{array}{l}\text { What methodology } \\
\text { governs the choice } \\
\text { in methods? }\end{array}$ & $\begin{array}{l}\text { What are the } \\
\text { techniques and } \\
\text { procedures used } \\
\text { to gather and } \\
\text { analyze data? }\end{array}$ \\
\hline
\end{tabular}

NOTE: The name of paradigm element is highlighted in black as the column heading; the question symbolizing the paradigm component is beneath name of paradigm element.

additional research methodologies are thoroughly explored within this book; however, let's analyze how a methodology could inform a method of researching. Two conventions embedded within the phenomenological research methodology include: (a) the importance of understanding the lived experience of individuals who have an understanding of the phenomenon, and (b) the researcher bracketing their understanding of the world in order to reduce the bias when observing the phenomenon in question. These standards for understanding participants' lived experiences could be realized if the researcher were to conduct semi-structured individual interviews with a group of people who have experienced the phenomenon in question. The bracketing of bias could partly be enacted if the researcher were to write down their bias and intra- and interpersonal experiences in a research journal at the beginning and end of each interview (Hays \& Singh, 2012).

Research methods are techniques and activities used to gather and analyze data. When considering research methods, one must ask, "What are the techniques or procedures used to gather and analyze data?" (Crotty, 2003). While this is the most pragmatic aspect of philosophical integration, it is our belief that this is the area of research design that helping professionals spend the most time formally learning about. As we create a detailed breakdown of the methods we will be using to uncover the information in question, it is vital that we have a direct connection with the overarching methodology and theory of the approach. Examples of methods can include those techniques used for data collection (e.g., survey, focus group, observation); data analysis (e.g., statistical analysis, open coding, textural description); sampling (e.g., random sampling, purposeful sampling, convenience sampling); trustworthiness (e.g., triangulation, data saturation, cross-validation); validity (e.g., content validity, criterion validity, discriminant validity); and reliability (e.g., test-retest, internal consistency, interrater reliability). Table 1.2 breaks down the major components of a research paradigm and provides an accompanying question that symbolizes the element.

\section{AXIOLOGY}

As you explore any given research paradigm, examining both the merit of your approach and the ethical decision-making procedure is central to every phase of your work. As a researcher, how do you know if what you are doing has value or worth? According to Heron and Reason (1997) axiology has to do with the nature of value and philosophically captures the notion of what is intrinsically worthwhile. In the world of research, axiology is centered on using aesthetics and ethics to shape the creative decision-making effort. Viega (2016) adds that axiology informs the ethical and visual decision-making process in the evaluation and design of qualitative research. According to Lincoln and Guba (2013), a researcher may ask the axiology-oriented question, 
"Given all of the data provided to me, what is the most valuable?" Another question might be, "Given the research problem and purpose, how can I strictly adhere to the ethical decision-making tenets of beneficence, justice, and respect?" (National Commission for the Protection of Human Subjects of Biomedical and Behavioral Research, 1978).

\section{QUALITATIVE PHILOSOPHICAL INTEGRATION}

There are many nuances to creating an appropriate qualitative philosophical integration. Schreier (2012) aptly describes this nuanced and diverse process: "Qualitative researchers are comfortable with the idea that there can be multiple meanings, multiple interpretations, and that these can shift over time and across different people" (pp. 20-21). Ontologically, realism and relativism often inform qualitative research design and constructionism and subjectivism are often the epistemological positions informing the qualitative theoretical stances of symbolic interactionism, phenomenology, feminism, post-modernism, and critical inquiry. There are numerous qualitative methodological frameworks (e.g., grounded theory, phenomenological research, narrative inquiry, ethnography); unique qualitative methodological stances within each methodology (e.g., Glaserian, Straussian, and constructivist grounded theory); and a host of data collection, analysis, sampling, and trustworthiness methods tailored to each approach. As you can see, there is no shortcut to having deep and widespread knowledge of these issues prior to conducting research. Developing expertise in a particular approach to research design often includes formal education (e.g., course work, reading scholarly publications); research mentorship (e.g., dissertation, thesis mentoring); and developing one's expertise through consulting and collaborating with colleagues who have diverse and in-depth expertise of the research framework.

You may be wondering how you will know if you are doing your philosophical integration correctly. Depending on the nuances and specifics of one's research study, there is variability regarding what should be nested with what. Ultimately, the expertise and judgment of the researcher are appraised and depended upon. It is the researcher's responsibility to provide the rationale and justification for creating a research paradigm. Researchers with a strong command of their research design will undoubtedly find this process easier than individuals who are new to a research approach. Those who have expertise in a particular methodology will thoroughly understand the differences and idiosyncrasies of each approach within that framework. While variability exists, there are inappropriate combinations; for example, it would be incorrect if a researcher were to combine the following: realism (ontology), objectivism (epistemology), post-modernism (theory), phenomenological research (methodology), and statistical analysis (methods). Within the aforementioned example, the theoretical stance of post-modernism would most likely not reside under the epistemology of objectivism, and a phenomenological methodology would not typically support statistical analysis as a method. Due to the core differences in these elements, this sequence would seem incompatible; however, as scientist practitioners, we always leave room for individuals to justify their rationale. Table 1.3 provides a concise breakdown of four (i.e., two qualitative, two quantitative) research paradigm possibilities. Following Table 1.3 we expand on common qualitative methods.

\section{QUALITATIVE SAMPLING METHODS}

Each chapter that promotes a particular research tradition, will provide for you a review of the sampling procedure(s) native to the particular methodological framework being explored. 
TABLE 1.3 Four Examples of Possible Research-Based Paradigms

\begin{tabular}{|l|l|l|l|l|l|}
\hline PARADIGM & ONTOLOGY & EPISTEMOLOGY & THEORY & METHODOLOGY & METHOD \\
\hline Qualitative & Relativism & Constructionism & $\begin{array}{l}\text { Symbolic } \\
\text { interactionism }\end{array}$ & $\begin{array}{l}\text { Grounded theory } \\
\text { research }\end{array}$ & Focus group \\
\hline Qualitative & Relativism & Subjectivism & Phenomenology & $\begin{array}{l}\text { Phenomenological } \\
\text { research }\end{array}$ & Interview \\
\hline Quantitative & Realism & Objectivism & Post-positivism & Survey research & $\begin{array}{l}\text { Statistical } \\
\text { analysis }\end{array}$ \\
\hline Quantitative & Realism & Objectivism & Post-positivism & $\begin{array}{l}\text { Experimental } \\
\text { research }\end{array}$ & $\begin{array}{l}\text { Testable } \\
\text { hypothesis }\end{array}$ \\
\hline
\end{tabular}

NOTE: Each column provides only one possibility, there are other relevant possibilities. The method column provides only one example, however, there are many different methods (e.g., validity, reliability, trustworthiness, data analysis, sampling) relevant to each tradition.

Qualitative researchers engage in non-probability sampling. As described earlier in this chapter, qualitative researchers believe randomized events are irrelevant to social life and humans are not predictable like objects (Merriam, 1998). Furthermore, because qualitative investigations are not centered on generalizing the results to a particular population, researchers are not concerned that each member of the population has a certain probability of being selected for the sample. Consequently, qualitative research participants are often selected because they are familiar (often deeply familiar) with the phenomenon under investigation. In the following, we briefly review a few of the most common purposeful and convenient qualitative non-probability sampling methods.

\section{Purposeful Sampling}

Qualitative purposeful sampling is an umbrella term to describe sampling strategies used to recruit individuals who have experienced the phenomenon or the construct being studied. The composition of the sample population can be based on the researcher's judgment, or it could be solicited through expert judges. Purposeful sampling strategies are often used on rare populations (Hays \& Singh, 2012; Schwandt, 2001).

\section{Criterion Sampling}

Criterion sampling is a form of purposeful sampling that ensures all participants are selected based on the fact that they meet a particular criterion. This form of sampling can be a helpful quality assurance method (Hays \& Singh, 2012; Schwandt, 2001). For example, a researcher may be interested in the parenting beliefs of African American fathers between the ages of 30 and 40. The researcher might use racial identity, parent status, and age as the criteria to participate.

\section{Maximal Variation Sampling}

Maximal variation is a form of purposeful sampling where the researchers intentionally recruit diverse individuals who are likely to hold different perspectives on the phenomenon in question. The idiosyncratic nature of the investigation dictates the amount to which the sample is maximized. The essence of this sampling approach is to diversify the findings as much as possible, thereby 
enriching the findings (Hays \& Singh, 2012; Schwandt, 2001). Using the same example, the researcher could further maximize the sample by adding groups of White fathers, Hispanic fathers, and older African American fathers.

\section{Theoretical Sampling}

Theoretical sampling is a third purposeful sampling method that uses a systematic process to sample a population in order to determine an emergent theory. Theoretical sampling begins with a particular criterion for recruitment, however this can change as the theory emerges. Once no new information presents itself, saturation has been achieved and data collection can stop (Hays \& Singh, 2012; Schwandt, 2001). For example, an initial sample criterion could be African American fathers between the ages of 30 and 40, however, after 15 semi-structured individual interviews, the researcher (or research team) may decide that a focus group of eight African American children should be conducted. After the focus group meets, the researcher may again decide to conduct a document analysis regarding research on parenting practices.

\section{Convenience Sampling}

Convenience sampling is an umbrella term used to describe sampling methods that are based on the researcher's ability to easily access a particular population. A clear benefit to this form of sampling is the ease in accessibility regarding the resources needed for the study (Hays \& Singh, 2012; Schwandt, 2001).

\section{Snowball Sampling}

Snowball sampling is a form of convenience sampling that depends on the research participant's relationships with individuals who have experienced the same or a similar phenomenon. The researcher inquires about these relationships to grow the sample size. As the name suggests, once the researcher finds a participant that meets the criterion, they will ask for references of other individuals who may have experienced the phenomenon. Snowball sampling is helpful if the participants in an investigation are difficult to locate (e.g., non-cooperative groups; Hays \& Singh, 2012; Schwandt, 2001). For example, if the researcher is exploring the post-war culture for veterans, they could use a single participant's personal references to increase their sample size.

\section{QUALITATIVE DATA COLLECTION PROCEDURES}

When qualitative researchers are collecting data, they are not interested in the generalizability, validity, and reliability of their findings. Instead, they are often concerned with the thickness and richness of the data collected and the naturalistic nature (studying people in their natural setting) of the inquiry. Thick data descriptions emerge when a researcher (or team of researchers) makes a detailed account of the data that are collected in the field. In addition, thickness refers to the amount of data that is collected (e.g., number of interviews). When researchers engage in an in-depth account of a phenomenon, they do not want it to be thin. Thin (i.e., vague, shallow, and lacking consensus) qualitative data can lack the credibility and confirmability that partly ensures the trustworthiness of the findings. It would not be uncommon for qualitative researchers to describe the thickness of their data by acknowledging the number of transcribed pages produced during 
a series of interviews. They also provide evidence of thickness within their in-depth description of the contextual factors (e.g., cultural patterns, social relationships) involved in a particular participant or group of participants (Holloway, 1997). This ensures the data collected are rich and demonstrates the complexities and intricacies of the data being explored. Rich data almost always demonstrate the researcher has intimate knowledge of the interpersonal and intrapersonal aspects of the participant's life (Given, 2008). Researchers seeking to enhance the richness of their data may develop the interview questions to have follow-up probes or can add a different form of data collection (e.g., focus group) to the overall analysis.

Qualitative researchers are highly concerned with the quality of their methods, analysis, and findings. Therefore, researchers engaging in qualitative research go to great lengths to describe, in detail, the various data collection methods (e.g., in-depth, semi-structured, individual interviews); the coordination of the data collection (e.g., participants were contacted individually via email); the environment where the data are being collected (e.g., the focus group took place in a confidential conference room); individuals involved (without identifying the participant); the date; and the length of time the researcher took in collecting the data (e.g., interviews ranged from 10 to 65 minutes in length). While the diversity and differences in the forms of data collection are clear, most qualitative traditions expect the data to be placed in tandem with other data collection points prior to analysis. In the following we review a few common qualitative data collection procedures.

\section{Individual Interview}

Individual interviews are the most common form of data collection in counseling qualitative research (Flynn, et al., 2019). Qualitative interviews are exploratory in nature and are used to discover social phenomenon. Most qualitative interviews use open ended questions and are semi-structured and/ or in-depth, however, structured interview questions and questionnaires are certainly supported qualitative methods. Similar to other data collection methods, qualitative researchers are sure to provide maximum details regarding the interview. For example, it would be common to see the time range of the interviews, date the interview was conducted, demographics of the participants, multiple examples of participant quotes, and a breakdown of the number of transcribed pages.

\section{Focus Group}

A focus group is when a collection of participants and a researcher explore a phenomenon in a group format. This dynamic interaction between participants and a researcher creates a new form of data (Hays \& Singh, 2012). This form of data collection gathers the subjective experiences of the participants, however there is an interaction between participants and the researcher that creates an original and nuanced data. When compared to individual interviews, the same level of detail is applied to focus group interviews, however the researcher must ensure that they have gathered data on every participant (e.g., screening, demographic, and contextual data).

\section{Artifacts}

Artifacts are often presented to the researcher in the form of a drawing, symbol, or a picture. Researchers are interested in collecting and analyzing the actual artifact and the participant's description of the artifact. During the data collection process, researchers will ask questions and probes about the artifact and its relevance to the investigation (Hays \& Singh, 2012). For example, 
in a qualitative research study on the dynamic interaction of altruism and self-interest, participants were asked to provide and describe a self-interest and altruistic artifact (Flynn \& Black, 2011).

\section{Document and Journal Analysis}

Document analysis is a data collection method that centers on reviewing documents relevant to the investigation. This form of data can be helpful in corroborating findings across data collection points (Hays \& Singh, 2012). Common examples include ethical codes, mission statements, annual reports, emails, blogs, list serves, and agendas. A journal analysis is a data collection method in which the researcher collects data through choosing relevant journal(s) and analyzing the articles that fall within a specified time-period (e.g., past 15 years). Similar to the analysis of an interview transcript, documents and journal articles are analyzed, coded, and added to the emergent themes.

\section{QUALITATIVE DATA ANALYSIS PROCEDURES}

The qualitative data analysis procedure that is incorporated into an investigation is dependent on the methodology being used. All major qualitative traditions have unique data analysis processes that are recommended; however, authors frequently augment their data analysis framework with unique procedures (e.g., coding scheme) and theories (e.g., feminism; see Flynn, et al., 2019). Examples of unique qualitative research data analysis frameworks include Colaizzi's (1978) sevenstep approach (phenomenology), Van Manen's (1990) six-step approach (phenomenology), constant comparison analysis (grounded theory), and open, axial, and selective coding framework (grounded theory). While there are many unique elements within each data analysis framework, all of the qualitative data analysis procedures that we reviewed share three common factors: coding (i.e., condensing data into small units); categorizing (i.e., clusters of coded data that share a theme); theming (i.e., higher level abstract categories that interrelate); and systematic connection of themes (i.e., depiction of the interrelation of themes; Jorgensen, 1989).

In a general sense, qualitative data analysis has to do with the researcher noticing, sorting, and thinking. When the researcher is at the noticing phase of any investigation, they may be making observations, writing field notes, recording interviews, and/or gathering documents. While the researcher is reviewing the information, they will notice something within the data that has an underlying meaning. They will code this information and place the information within a codebook. Next, the researcher will begin sorting the coded data into clusters of information that share some commonality. Once the data become somewhat manageable (i.e., a large number of clusters), the researcher will begin breaking up, separating, and re-organizing the clusters into meaningful themes. At this point the researcher will attempt to think about the emergent themes and try to refine and make sense of the information. The researcher will look for patterns and relationships across the data set. Once the finalized themes and secondary themes are in place, the researcher will attempt to determine how the data systematically work across themes and determine the relationships between themes and larger domains (Seidel, 1998).

\section{TRUSTWORTHINESS PROCEDURES}

According to Schwandt (2001), qualitative trustworthiness is the description given to a set of criteria that appraises the quality of qualitative research. Trustworthiness has to do with a qualitative 
study's rigor and reliability of the data, methods, and interpretations. While there is no prescribed procedure that ensures $100 \%$ trustworthiness, the researcher works to establish criteria necessary for a study to have legitimacy (Polit \& Beck, 2014). Lincoln and Guba (1985) created criteria for ensuring trustworthiness. These criteria include credibility, dependability, confirmability, and transferability; they later added authenticity (Guba \& Lincoln, 1994). In the following we provide descriptions of Guba and Lincoln's criteria and provide one example of how to execute a procedure during qualitative research study.

The credibility of an investigation is the confidence in the accuracy of the study procedures and findings. This form of qualitative trustworthiness is similar to the quantitative research process of internal validity. The use of a reflective journal, member checking, and peer debriefing are all techniques used to establish the credibility of an investigation (Polit \& Beck, 2014). Member checking is when a researcher sends participants a copy of the interview transcript, a breakdown of the emergent themes and secondary themes, and examples of the emergent themes within the interview transcript. Participants are then invited to engage in a dialogue regarding the researcher's interpretation of the interview. Participant perceptions are taken into consideration and themes are further refined.

According to Schwandt (2001), confirmability demonstrates qualitative objectivity and the neutrality of the findings. In other words, it is important to demonstrate that the conclusions derived from a study were not developed by the researcher. Methods for ensuring confirmability include memos, audit trail, and triangulation (i.e., examining data from multiple perspectives). Triangulation is a process that, in theory, should take data from a variety of sources and eventually converge on some level of certainty. Krefting (1991) found data methods to be the most common type of triangulation. An example of this form of confirmability would be to examine a construct (e.g., the psychology of carpet color) through several data collection methods. For instance, the researcher's explored carpet color's effect on mood through 15 in depth semi-structured interviews, two focus groups, and participant artifact reviews. Results were triangulated among these three data collection points and the findings confirmed the emergent themes.

Dependability requires qualitative research to be traceable, logical, and documented. This ensures the data are stable over time and are similar to the quantitative construct of reliability. Examples of dependability include process logs, dependability audits, and peer debriefings (Polit \& Becker, 2014). Peer debriefing is beneficial in creating a reliable understanding of the phenomenon. This method would require the researcher to seek multiple peers who hold impartial views of the topic. Peers would be sent the transcripts, emergent themes and secondary themes, and directions on how to provide peer feedback. The peer feedback is funneled into the analysis to enhance the dependability of the findings.

Transferability is the qualitative version of external validity and attempts to see if phenomena can be transferred from case to case. This is not to say that the qualitative data will generalize to a larger population; however, it does attempt to ensure that the individuals involved in the study did have data transfer from and among cases (Schwandt, 2001). Transferability can be ensured through detailed, rich, and thick descriptions of the findings, procedures, and research setting. One aspect of providing rich and thick descriptions of the phenomena can include thoroughly defining a theme, including secondary themes, and providing multiple quotes that symbolize the themes.

Lastly, authenticity is the degree the researcher accurately portrays the participant's life (Polit \& Beck, 2014). Deep and contextually accurate descriptions of all elements of the research process convey authenticity. An example of authenticity could be a clear statement indicating the rationale for the sample size. 


\section{QUANTITATIVE PHILOSOPHICAL INTEGRATION}

Quantitative researchers tend to have a consistent philosophical integration. Ontologically, realism informs their research philosophy, while objectivism is the primary epistemological position informing the quantitative theoretical stances of positivism and post-positivism. There are a plethora of quantitative methodological frameworks, including (but not limited to) experimental research, survey research, predictive designs, single subject design, and certain content analysis traditions. Within each methodological framework are methods centered on enhancing the generalizability of the findings through statistical formulations. Quantitative researchers aim to create rules, so they can ascertain the framework for generalizability and prediction. The essence of most quantitative frameworks is a deductive approach to data, and correlation and experimentation are used to deduce complex social constructs (Crotty, 2003; Scotland, 2012). Scotland (2012) provides a clear and concise description of the essence of quantitative procedures.

[Quantitative] Research is deemed good if its results are due to the independent variable (internal validity), can be generalized/transferred to other populations or situations (external validity), and different researchers can record the same data in the same way and arrive at the same conclusions (replicable and reliable). Additionally, research needs to be as objective as possible and robust to empirical refutation (p. 11).

Unlike the appreciation of multiple realities or a subjective reality that is embedded within the qualitative philosophical integration, objectivists believe that there is absolute knowledge and truth in the world. The objectivist knowledge is outside of one's subjective perceptions, and the cultural/perceptual lens one touts plays very little in the construction of reality. Consequently, a goal of the quantitative researcher is to impartially discover the meaning objects in the world (Scotland, 2012). These objects are knowledge and facts and are free of subjective values and biases. Theoretically, most quantitative research conducted in the social science is centered on a post-positivistic framework. Post-positivists believe that the knowledge produced in research is not absolute truth; it is the researcher's belief in the tested hypothesis (Popper, 1959). Furthermore, post-positivists believe that scientific results are not truth; they are tentatively accepted statements. This tentative acceptability of knowledge is based on the philosophy of the principle of falsification. Falsification suggests that for things to be scientific they must be able to be proven false (Popper, 1959).

Quantitative researchers investigate variables. A variable is an event or object that is liable to change (https://techterms.com/definition/variable). A variable could refer to a wide variety of things (e.g., level of depression, climate change, hair growth). In algebraic equations, variables are often symbolized as " $x$ " or " $y$ " and one variable is often dependent on the value of another variable. Similarly, quantitatively oriented researchers are interested in the relationship between independent and dependent variables. Independent variables are objects that are manipulated by researchers and the effects are measured or compared. Dependent variables are what measures the effect of the independent variable(s). Dependent variables are dependent on independent variables. For example, if you decided to research the effects of daily vitamin $\mathrm{C}$ consumption on level of persistent depressive disorder among a sample of middle-aged persistently depressed women, your independent variable would be daily vitamin $C$ consumption and your dependent variable would be level of depression. In this example, you would measure the independent and dependent variable with an approved quantitative data collection method (e.g., survey, observation, experiment) so the information produced would be numerical and eventually statistical. 


\section{QUANTITATIVE SAMPLING METHODS}

The sampling methods that most individuals hear and know about are quantitative in nature. Please recall the previous description of probability theory and the notion that quantitative researchers are interested in the nature of randomness. Consider that just about every statistical test relies on probability concepts and researchers are very attentive to the level of uncertainty any research process has (Hurlburt, 2017). Quantitative researchers are interested in every member of a population having an equal chance of being selected to participate in a given study. They are typically attentive to developing procedures that create a representative sample of a larger population of interest. A population is the group that is the focus of the researcher and a sample is some subset of that group. This subset is not chosen in a purposeful or convenient manner; rather, it is chosen by chance because it represents, in some way, the larger population. Quantitative researchers make great efforts to reduce any bias that might sneak into their choice of sample. In other words, they focus on setting aside their personal preferences of a sample's composition in favor of a purely chance method of selecting a population (Hurlburt, 2017). In the following we briefly review a few of the most common quantitative probability sampling methods.

\section{Simple Random Sampling}

Simple random sampling is a frequently used method of sampling in which a subset of individuals, from a population of interest, is statistically selected in a manner that is random and completely by chance. In a simple random sample, every individual in the population has an equal probability of being chosen (Hurlburt, 2017). For example, if a researcher wants to investigate the outcomes of dissociative fugue treatment in the United States, they might start by making a list of all inpatient psychiatric units in the United States. Next, they develop a sampling frame by giving a number to each psychiatric unit. They would then determine the right sample size. Lastly, using a random number generator, the researcher(s) would select a sample.

\section{Stratified Random Sampling}

Stratified random sampling is a method of random sampling that divides the population of interest in strata (i.e., small subgroupings) that reflect the shared demographics (e.g., education, gender, income) of the population of interest. An important difference between simple and stratified random sampling is that stratified sampling is used to draw attention between sub-groups (i.e., strata). In comparison, simple random sampling is centered on the equal probability of being sampled. For example, if a researcher wanted to conduct a study on incarcerated U.S. males, the researcher could use a stratified random sample. They would initially look up the population demographics of American male prisoners. Next, they would use statistics to divide their participants into strata based on the population demographics (e.g., race, ethnicity, socioeconomic status). The strata can either be a proportional stratified sample (i.e., size of strata proportionate to the population) or a disproportional stratified sample (i.e., size of the strata is not proportionate to the population).

\section{Cluster Random Sampling}

Cluster random sampling is a method where a sample of various groupings, based on a population of interest, is comprised of all or close to all members of a population. An important difference 
between stratified and cluster random sampling is cluster sampling does not need to have equal selection from each subgroup of the population within the sample; however, with cluster sampling, the entire population of interest should be involved (Hurlburt, 2017). In addition, cluster sampling cannot have participant cross-over. In other words, each participant should only have membership in one cluster sample. Lastly, while stratified sampling is used with demographics, cluster sampling can be based on any categorization (e.g., interests, astrological sign, hobbies, opinions; https:// study.com/academy/lesson/cluster-random-samples-definition-selection-examples.html). For example, a researcher would like to know the political views of a local high school. The researcher wants information from the different grade levels (freshman, sophomores, juniors, and seniors). In this example, none of the students are members of more than one grade and all of the students are members of a particular grade.

\section{Multistage Random Sampling}

Multistage random sampling involves the grouping of mini clusters of a population of interest. The researcher chooses one of the clusters at random to sample, and sampling units become progressively smaller at each stage. Multistage random sampling is often a combination of random, stratified, and cluster sampling methods (https://www.statisticshowto.datasciencecentral.com/ multistage-sampling/). For example, a researcher wants to explore which color American school children prefer. The first stage could include the researcher dividing the population into states and taking simple random samples from each state. Next, the researcher could take a simple random sample of schools within each state. For last stage, the researcher could conduct a simple random sample of the children within each school.

\section{QUANTITATIVE DATA COLLECTION PROCEDURES}

When quantitative researchers are collecting data, they are interested in the generalizability, validity, and reliability of their results. Instead of the open-ended and exploratory nature that embodies the essence of qualitative data collection procedures, quantitative data collection is centered on answering a hypothesis through tools (e.g., survey) that capture a numerical value (e.g., Likert scale). Quantitative data can be considered objective and conclusive because it is numerical in nature. Statistical computations turn the numbers gathered into comprehendible knowledge (often with help of graphs, tables, and charts). In the following we describe a few of the most common quantitative data collection procedures.

\section{Survey}

Survey data collection approaches are systematic methods for collecting data on a population of interest. The direct nature of survey research gives it an edge with determining trends within populations, relationships among variables, and comparison groups. Survey researchers take great care that the ordering and wording of questions does not create biased results. The methods used for survey research includes (but are not limited to) online survey, paper-and-pencil survey, computer assisted interviewing, face-to-face surveys, and mail surveys. Questionnaires are often self-administered, and interviews are delivered in a consistent manner by the interviewer. Decisions on whether or not to use questionnaires or interviews can be partly determined by the survey design (longitudinal, cross-sectional; Creswell \& Plano Clark, 2017). 


\section{Observation}

A controlled observational study has to do with quantitatively observing the participant(s) (i.e., variables of interest), and gathering data on them in a controlled setting. Researchers agree on behaviors to observe and a scale to measure the behavior. Researchers will then observe the controlled participant(s) and code their interaction and behaviors based on the agreed upon items and scale. The discrete categories on the scale are used to turn the observation into numbers and later into statistics (Hurlburt, 2017).

\section{Experiment}

Experimental research (i.e., true experiment) is conducted with a clear understanding of the variables the researcher wants to test and then measure. In addition, there is a random assignment or preselection of participants to groups. In an experiment, a researcher will create a treatment group and observe the response on the participants. In addition, the researcher may also create a control group. The control group does not receive the treatment or will receive a placebo. Comparisons can be made between these two groups. A related form of research is the quasi experiment. This form of research is often used in the behavioral sciences. The researcher(s) do not use a random assignment with this form of research. Instead, the researcher manipulates something within the participant group to observe the consequences (Hurlburt, 2017).

\section{QUANTITATIVE DATA ANALYSIS PROCEDURES}

You may be wondering what happens once the quantitative data are collected. A researcher will turn their attention to the analysis of data. Similar to qualitative traditions, quantitative data analysis procedures are in line and dependent on the quantitative methodology being employed. All major quantitative traditions have unique data analysis procedures that are recommended. In a general sense, quantitative data analysis is a systematic method that transforms what was collected or observed into numerical data and the numerical data is then categorized in some comprehendible way. Quantitative analysis is the analytic aspect of the investigation that gets to the core of whether or not a researcher(s) findings support or fail to support an idea or a hypothesis. While quantitative data can be analyzed in a variety of different ways, the general essence involves measuring quantities that answer the "why," "what, and "how many" questions a researcher may have about something.

In regard to statistical analysis, there are two broad classifications: descriptive statistics and inferential statistics. Descriptive statistics is centered on describing a data set and avoids making conclusions. Typically, this description of the data involves the measures of central tendency (e.g., mean, median, mode) and measures of dispersion (e.g., variance, standard deviation). The essence of inferential statistics is using a sample to test a hypothesis in order to make inferences about a population. Since inferential statistics is aimed at making inferences about a larger population, it is very important to attain a representative and large sample. While some error is inevitable in any statistical computation, it is significantly improved through sample size and representation (https://www.mymarketresearchmethods.com/descriptive-inferential-statistics-difference/). Inferential statistics usually include sophisticated tests, including (but not limited to) T-Test, ChiSquared, ANOVA, two-way-ANOVA, ANCOVA, MANOVA, and regression (Hurlburt, 2017). These concepts are thoroughly reviewed in Chapter 4. 


\section{VALIDITY AND RELIABILITY}

The quantitative constructs of validity and reliability are covered thoroughly in Chapter 4; however, given their importance in quantitative research, we will briefly describe each here. Validity has to do with the degree you are measuring what you are supposed to be measuring. Cook and Campbell (1979) define validity as the "best available approximation to the truth or falsity of a given inference, proposition or conclusion" (p. 37). For example, a depression inventory should measure depression. The degree to which it does measure the construct of depression, and not something else, is its level of validity.

While there are a variety of validation procedures used to assess the validity of a test (e.g., criterion validity, construct validity, predictive validity, concurrent validity), an important distinction that we will make in this chapter is between internal and external validity. Internal validity is the estimate of a causal relationship between the independent variable(s) (i.e., the variable(s) being manipulated) and dependent variable(s) (i.e., what is being measured). In a general sense, the level of internal validity refers to whether the effects of the research are due to the manipulation of the independent variable and not some other external factor (e.g., loss of job, sudden death in the family). Researchers are investigating the strength of the causal relationship between the independent and dependent variable(s), and, through controlling extraneous variables (i.e., variables not deliberately studied), they attempt to improve internal validity. Comparably, the level of external validity refers to the level of positivity that a study's results can be generalized to diverse settings, people, and over times. Researchers work to improve the external validity of their work through random sampling and conducting research in a more natural setting (Hurlburt, 2017).

Reliability, on the other hand, approximates the consistency of your estimates. In other words, reliability is the degree to which an instrument produces the same results when used more than once. An assessment is considered to be reliable if its use on the same sample/object consistently produces the same results (Hurlburt, 2017). Similar to validity, there are a variety of procedures used to assess the reliability of a test (e.g., test re-test reliability, parallel forms reliability, inter-rater reliability, internal consistency reliability). These concepts, and much more, will be explored in Chapter 4 .

\section{MIXED METHODS PHILOSOPHICAL INTEGRATION}

The third behavioral science methodological movement, following quantitative and qualitative research, is mixed methods research (Tashakkori \& Teddlie, 2003). In comparison to quantitative and qualitative methodology, mixed methods methodology is very new to the world of research. While the first known mixed methods research project may have been Campbell and Fiske's (1959) model of multitrait-multimethod matrix (MTMM), during the 1980s the combination of qualitative and quantitative methods began to gather a lot of attention in the world of research (see Greene, Caracelli, \& Graham, 1989). In a general sense, mixed methods research design is the notion that qualitative and quantitative methods can be combined, in a complementary manner, to produce unique knowledge beyond what one methodological framework could do alone.

You may be asking yourself, "How do the previously discussed philosophical integration models fit in with a methodological framework that can combine qualitative and quantitative methods?" That is a great question. Truly, from a paradigm perspective, mixed methods research is an iterative and inductive moving target. One approach has a primarily quantitative thread and a smaller qualitative aspect, while another approach touts a main qualitative component and a less 
significant quantitative element. This mixing of methods does not fit neatly into a paradigmatic hierarchy. Consequently, the philosophy of pragmatism often guides mixed methods research (Biesta, 2010; Maxcy, 2003). Instead of the creation of paradigmatic camps (i.e., qualitative and quantitative), mixed methods often purport that whatever works should guide research processes (i.e., pragmatism). In short, to echo Johnson and Onwuegbuzie (2004), mixed methods research takes a pragmatic and pluralistic position that provides the flexibility to further advance the discovery of knowledge.

Pragmatism does not fall into the traditional philosophical integration (ontology, epistemology, theory, methodology) that qualitative and quantitative traditions are centered on. Fitting pragmatism into the paradigmatic hierarchies that govern other research traditions would be antithetical (Dewey, 1929). According to Hall (2013) pragmatism, as a paradigm, directs researchers to take action and experience a situation prior to making meaning of it. Consequently, the notion of pluralism becomes relevant if the situation is deemed to need such action. An example of pluralism (i.e., two or more systems co-existing) can be seen when combining both qualitative and quantitative methods to a research process (Morgan, 2014).

\section{MIXED METHODS SAMPLING AND DATA COLLECTION METHODS}

Mixed methods sampling and data collection possibilities are dictated by the researcher(s) belief in what will maximize the understanding of a phenomenon. Mixed methods research design has at least two points (qualitative and quantitative) in which data are collected. Chapters 15 through 18 of this textbook cover major mixed methods research traditions, including the sampling and data collection methods native to each approach. Within each chapter, the order of operations native to the particular mixed methods research approach are discussed. For example, in an explanatory mixed methods design, the researcher first collects quantitative data, and after analyzing the quantitative data, will follow up with qualitative data collection. Within these mixed methods approaches, a combination of qualitative and quantitative sampling procedures, previously reviewed, will either be combined or used at various points (e.g., first phase is quantitative, and second phase is qualitative) in the research process. Within this example, the researcher(s) could use a simple random sample within the first phase of the project and a criterion sample within the second phase. See Table 1.4 for a quick review of the common probability (quantitative) and non-probability (qualitative) sampling methods that mixed methods researchers can choose from. Similarly, mixed methods researchers use a combination of data collection methods; usually both quantitative (e.g., survey) and qualitative (e.g., individual interviews) methods will be combined to converge on a better understanding of the phenomenon. Lastly, validation and trustworthiness procedures are used, within the appropriate phase, to ensure results are trustworthy, valid, and reliable.

\section{RIGOR}

Many beginning researchers have been disappointed and discouraged by the research process because they have been rejected by a journal or their dissertation/thesis committee has slowed down or, in some cases, prohibited their progress toward fulfilling their degree requirements (Flynn, Chasek, Harper, Murphy, \& Jorgensen, 2012). Oftentimes, these research-based 


\section{TABLE 1.4 Common Probability and Non-Probability Sampling Methods}

\begin{tabular}{|c|c|c|c|}
\hline & $\begin{array}{l}\text { NAME OF SAMPLING } \\
\text { METHOD }\end{array}$ & $\begin{array}{l}\text { PROBABILITY OR } \\
\text { NON-PROBABILITY }\end{array}$ & DESCRIPTION \\
\hline 1 & $\begin{array}{l}\text { Simple Random } \\
\text { Sampling }\end{array}$ & Probability & $\begin{array}{l}\text { This method of sampling is randomized. } \\
\text { Randomization could involve using a } \\
\text { randomized number generator in order to } \\
\text { select numbers. }\end{array}$ \\
\hline 2 & $\begin{array}{l}\text { Stratified Random } \\
\text { Sampling }\end{array}$ & Probability & $\begin{array}{l}\text { This method of sampling divides } \\
\text { population into smaller sub-groups and } \\
\text { then uses simple random sampling to } \\
\text { choose subjects from the groups to select } \\
\text { the sample. }\end{array}$ \\
\hline 3 & Systemic Sampling & Probability & $\begin{array}{l}\text { This method of sampling required selecting } \\
\text { every "nth" participant from the population } \\
\text { to complete your sample. }\end{array}$ \\
\hline 4 & $\begin{array}{l}\text { Cluster Random } \\
\text { Sampling }\end{array}$ & Probability & $\begin{array}{l}\text { In cluster random sampling, the researchers } \\
\text { select a cluster to sample from instead of } \\
\text { the entire population. }\end{array}$ \\
\hline 5 & $\begin{array}{l}\text { Multi-Stage Random } \\
\text { Sampling }\end{array}$ & Probability & $\begin{array}{l}\text { This method of sampling uses a mixture of } \\
\text { all sampling techniques. }\end{array}$ \\
\hline 6 & Convenience Sampling & Non-probability & $\begin{array}{l}\text { This method of sampling uses participants } \\
\text { that are conveniently accessible to the } \\
\text { researcher. }\end{array}$ \\
\hline 7 & Purposive Sampling & Non-probability & $\begin{array}{l}\text { This method of sampling uses the } \\
\text { researcher's own judgment to select what } \\
\text { they feel will be the most suitable sample } \\
\text { for the study. }\end{array}$ \\
\hline 8 & Expert Sampling & Non-probability & $\begin{array}{l}\text { This method of sampling uses experts from } \\
\text { the field related to the study, selected by } \\
\text { the researcher. }\end{array}$ \\
\hline 9 & Heterogeneity Sampling & Non-probability & $\begin{array}{l}\text { This method of sampling purposefully } \\
\text { selects participants to represent all } \\
\text { perspectives in the sample. }\end{array}$ \\
\hline 10 & Modal Instance Sampling & Non-probability & $\begin{array}{l}\text { This method of sampling takes the most } \\
\text { "common" participants for the sample. }\end{array}$ \\
\hline 11 & Quota Sampling & Non-probability & $\begin{array}{l}\text { This method of sampling represents } \\
\text { demographics proportionally. }\end{array}$ \\
\hline 12 & Snowball Sampling & Non-probability & $\begin{array}{l}\text { This method of sampling allows } \\
\text { participants to recruit further participants } \\
\text { for the sample. }\end{array}$ \\
\hline 13 & $\begin{array}{l}\text { Maximum Variation } \\
\text { Sampling }\end{array}$ & Non-probability & $\begin{array}{l}\text { This method of sampling allows for the } \\
\text { selection of individual, group, and setting } \\
\text { to maximize the diversity of perspective. }\end{array}$ \\
\hline 14 & Theory-Based Sampling & Non-probability & $\begin{array}{l}\text { This method of sampling allows for the } \\
\text { inclusion of participants that help a theory } \\
\text { develop. }\end{array}$ \\
\hline 15 & Extreme Case & Non-probability & $\begin{array}{l}\text { This method of sampling allows for the } \\
\text { selection of outlying cases. }\end{array}$ \\
\hline
\end{tabular}

NOTE: This table contains 15 concise sampling descriptions. Further reading is necessary to fully understand each approach. 
rejections are centered on design flaws, including (but not limited to) poorly formulated research questions, non-optimal instrumentation, and/or unreliable and weak methods. In addition, there are instances where the researcher simply is not doing enough. It could be that the research is not adding enough originality to our collective scholarly knowledge. These projects are often labeled unoriginal, predictable, lacking implications, and/or trivial. Furthermore, research can seem thin and unsubstantial if the number of participants is low and the results cannot be generalized to a particular population (quantitative research), or if the methods being used lack depth and diversity (qualitative research; Flynn et al., 2019; Laher, 2016). In many of the aforementioned circumstances, the research can be made acceptable and appropriate if additional rigor is added.

\section{QUANTITATIVE RIGOR}

One important way this textbook enhances your understanding of each research tradition is through describing how to increase the rigor of each approach. Rigor, in research, generally refers to the processes followed to ensure integrity, soundness, and legitimacy of a project (Laher, 2016). Quantitative rigor is centered on the development of the project, how clear and objective the methods are, how detailed the research design is described, and how well the researcher(s) adhere to the rules of the particular research tradition (Laher, 2016). In addition, quantitative researchers, who are interested in increasing the rigor of their investigation, pay scrupulous attention to the systematic design of the approach as it relates to answering the research question(s), choosing the most optimal method or design for the problem and population being investigated, large and appropriate chosen sample size and/or design, and ensuring the data are both complete and reliable.

While there a variety of factors that contribute to the rigor of quantitative research, internal validity, external validity, and replicability are at the core. Understanding eliminating the various threats to internal validity and external validity can greatly enhance a study's rigor. Five main threats to internal validity include: history (i.e., environmental changes pre/post-test); maturation (i.e., changes that take place over the time of an experiment); attrition (i.e., effect of dropout rates); selection bias (i.e., unequal number of participants have similar attributes); and diffusion (i.e., when the comparison group learns about the experiment group; Babbie \& Mouton, 2004). External validity evaluates the generalizability of results to and across individuals (population validity), settings (ecological validity), and time. Threats to external validity can come in the form of an interaction effect of testing. In these instances, results may not generalize because pre-testing interacts with the experimental treatment group. A second threat to external validity could be in the form of reactive effects of the experimental arrangements. For example, the Hawthorne effect can change participant's natural behavior due to the novelty of experiencing the research process. Lastly, replicability refers to the extent to which the same or similar results would be obtained if the same study was conducted somewhere else. Issues that are common threats to replicability include research with low statistical power and poorly described methods sections (Coryn, 2007).

\section{QUALITATIVE RIGOR}

Qualitative rigor refers to the extent to which an investigation presents a rigorous methodology, analysis, and trustworthiness. Anyone conducting an article review on the rigor associated with qualitative and quantitative research will quickly realize that there are far more articles concerning 
qualitative rigor. Why is there a greater focus on establishing rigor in qualitative research? According to Guba (1981) the constant efforts aimed at understanding and enhancing qualitative rigor is due to the nonexperimental nature of qualitative research. As we mentioned earlier in the chapter, Lincoln and Guba (1985) attempted to enhance qualitative research through developing criteria to ensure rigor (i.e., credibility, confirmability, dependability, transferability, and authenticity). In addition to these criteria and the associated trustworthiness strategies, qualitative rigor can be ensured through the use of diversity in data collection methods (e.g., individual interviews, focus groups, document analysis, and artifact analysis) and engaging in multiple iterations of the same data collection method (e.g., multiple individual interviews with the same participants; Flynn, et al., 2019). These diverse and in-depth methods help to ensure thick and rich descriptions, greater understanding of the phenomenon, and create an in-depth triangulation of data (see Figure 1.2).

Qualitative trustworthiness procedures are designed, in part, to enhance the rigor of an investigation. Most trustworthiness procedures are centered on the researcher completing tasks to enhance the rigor of the investigation. Examples of researcher-centered trustworthiness procedures include prolonged engagement (i.e., spending time observing and developing rapport with participants); thick description (i.e., a detailed account of field-based context); the reflection of researcher bias (i.e., exploring and bracketing bias to ensure trustworthiness); negative case analysis (i.e., analyzing data to demonstrate the opposite of a theme); reflexivity (i.e., constantly examining perceptions and its connection with research decisions); epoche (i.e., internally suspending judgment); and triangulation (i.e., exploring the same topic with multiple methods). Two additional trustworthiness strategies that are non-researcher centered include member checking and auditing (i.e., dependability audit, inquiry audit, and confirmability audit). Member checking is conducted with the participants to confirm the credibility of the findings. Audits are conducted with an auditor after the completion of an aspect or the entirety of the research process to confirm the credibility and dependability of the investigation (Creswell, 2012; Hays and Singh, 2012). While there are very few standards addressing how to use various trustworthiness strategies, there is evidence suggesting that qualitative researchers should use at least two strategies in any study (Creswell, 2012).

\section{MIXED METHODS RIGOR}

As you probably guessed, qualitative and quantitative standards of rigor both apply to mixed methods research. Qualitative standards of rigor (e.g., credibility, confirmability, dependability, transferability, authenticity) apply to the qualitative methods and quantitative standards (e.g., validity, reliability, replicability, generalizability) apply to the quantitative methods. Researchers implement qualitative and quantitative components either concurrently or sequentially, with the same sample or with different samples. In addition, mixed methods research adds the element of mixing to rigor. Mixing is the process of the qualitative and quantitative phases interacting to produce a dynamic and enhanced account of the research (Zhang \& Creswell, 2013). In addition to mixing data appropriate to each method's tradition, researchers must both plan and justify their integration.

Once the separate qualitative and quantitative threads are demonstrating appropriate rigor and merit, mixed methods researchers ensure the mixing phase is rigorous. When mixing qualitative and quantitative results, mixed methods researchers often use the process of qualitatizing of quantitative data or the quantitizing of qualitative data to create meta-inferences (Onwuebuzie \& Johnson, 2006). From a rigor perspective, mixed methods researchers are focused on both the design quality and interpretive quality. Design quality has to do with ensuring the mixed methods tradition was appropriately applied and interpretive quality is centered on the mixing interpretation (Tashakkori \& Teddlie, 2003). 

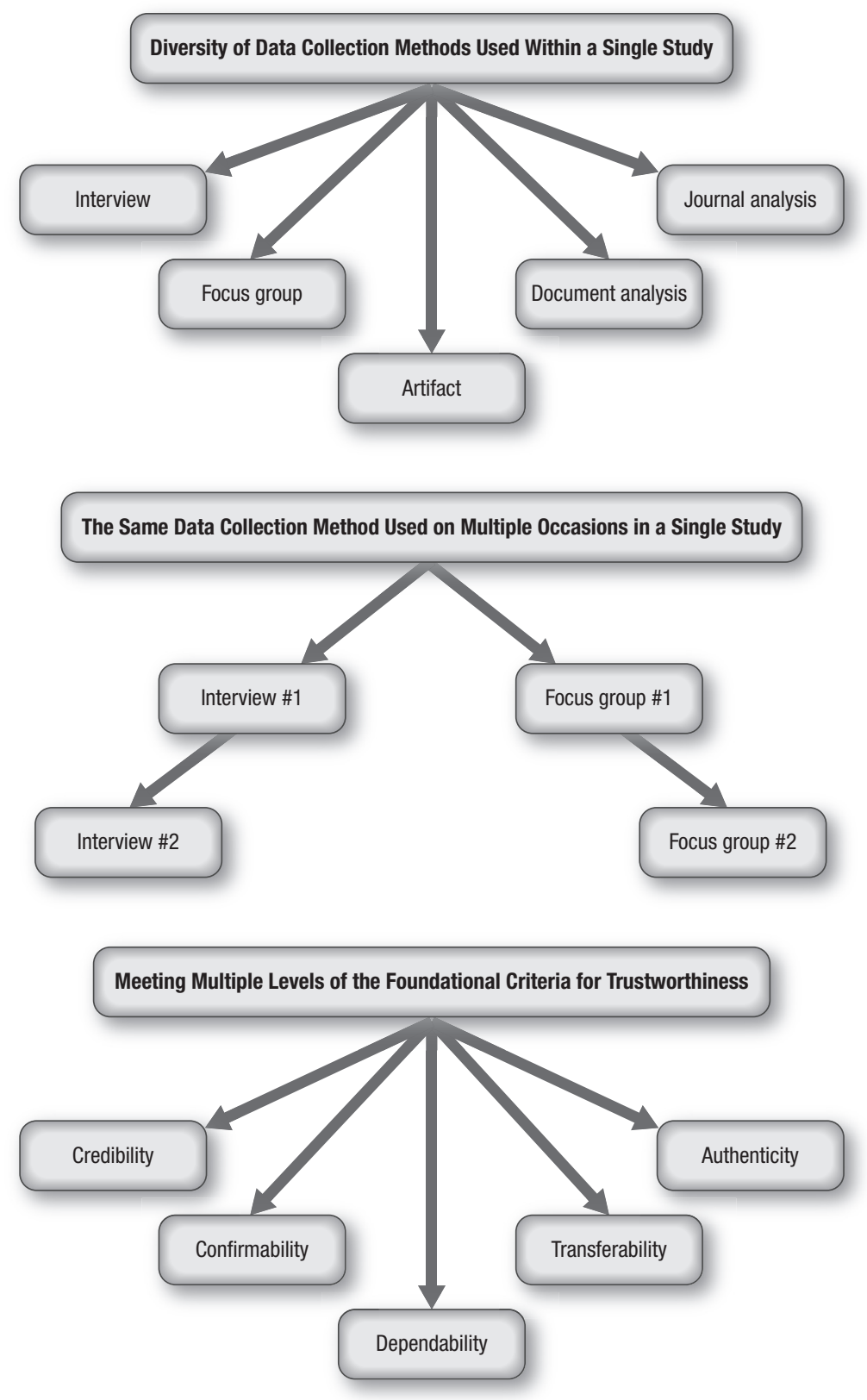

FIGURE 1.2 Three Strategies for Attaining Qualitative Rigor.

NOTE: Each representation symbolically demonstrates a unique way to achieve qualitative rigor.

\section{PILOT STUDY}

Pilot studies are a final area of inquiry that qualitative, quantitative, and mixed methods traditions use to create higher levels of investigatory rigor (Ismail, Kinchin, \& Edwards, 2017). The essence of a pilot study or feasibility study is to conduct a smaller investigation that provides feedback to a larger research project. Pilot studies include conducting smaller forms of a full research study 
and the pretesting of appraisal instruments. The nature of this feedback helps the researcher(s) to make adjustments and refine the methodology and methods prior to engaging in the full study. Well-executed pilot studies provide an investigation with methodological rigor by ensuring the study itself and the methods provided are valid and/or trustworthy. Although conducting a pilot study does not guarantee rigor, it greatly increases the likelihood of both validity and success. While common in all research traditions, pilot studies are much more prevalent in quantitative investigations (Ismail, Kinchin, \& Edwards, 2017).

\section{RESEARCH METHODOLOGICAL IDENTITY}

As previously discussed, the counseling profession has been placing a lot of attention on the construct of professional identity. Counselor research identity has been promoted within doctoral training programs (Lambie, Hayes, Griffith, Limberg, \& Mullen, 2014), master's level training programs (Jorgensen \& Duncan, 2015), and within the American Counseling Association (ACA) Code of Ethics, counselors are called upon to embrace the scientific aspects of the counseling profession (ACA, 2014). This identity emphasis within the aforementioned scholarship and professional standards is centered on the development of the counselor; however, within this section, we turn your attention to the identity of a particular research tradition. The nature of a particular approach has a lot to do with its history, the leaders who have influenced the creation of the tradition, the manner in which a particular field uses the methodology to better understand topics of interest, which groups are sampled, and what methods are emphasized when using a particular tradition (see Figure 1.3).

In Chapter 2 of this textbook, we explore the foundations of social science research, including philosophy, pioneers, and legacies. The unique history and foundation that each research tradition has greatly informs the manner and style in which the methodology is conducted. For example, the philosophical roots of phenomenology has its origins in the writings of René Descartes (15961650), David Hume (1711-1776), Immanuel Kant (1724-1804), and Edmund Husserl (18591938), while positivism has some of its philosophical roots in the writings of Pierre-Simon Laplace (1749-1827) and Auguste Comte (1798-1857; Crotty, 2003). In addition to the vast legacies of foundational scholars, different helping professions use research traditions to uncover unique information. According to the results of a recent investigation, the counseling profession most often

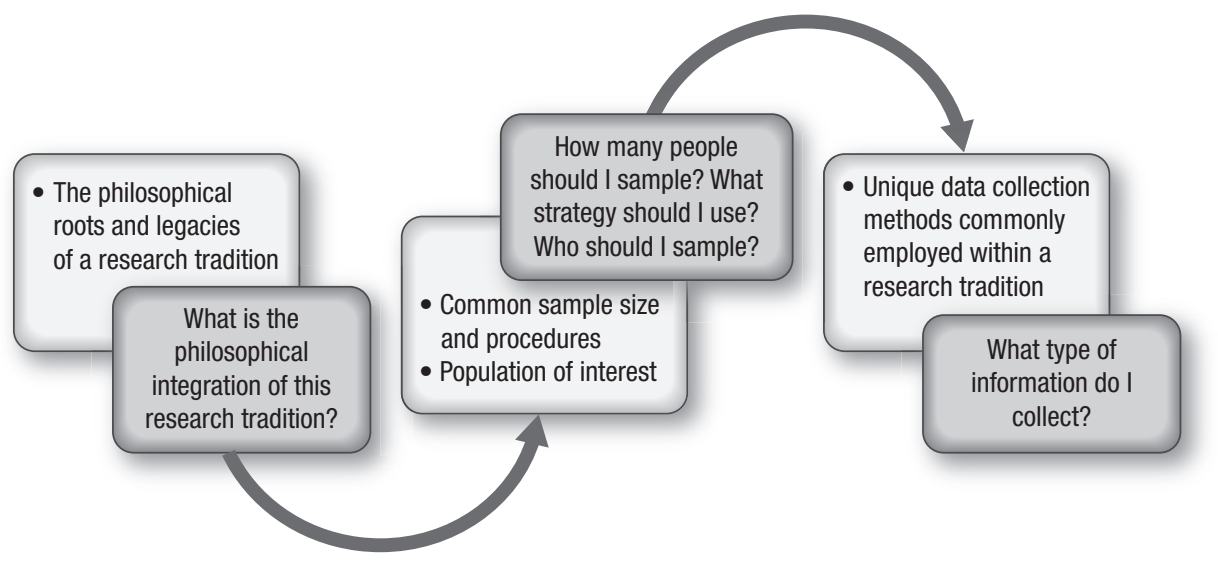

FIGURE 1.3 The Nature of Methodological Identity.

NOTE: Each white rectangle represents a unique aspect of methodological identity. The dark rectangles include questions indicateing what the researchers are asking themselves. 
explored the topics of multiculturalism when using the research traditions of phenomenology and consensual qualitative research, and pedagogy when using grounded theory (Flynn et al., 2019). While the philosophy and topic patterns are only two aspects of methodological identity, they start to paint a distinct picture of the character of each approach.

\section{Best Approach for Problem Versus Best Approach for a Researcher}

There can be a considerable amount of dissonance with the manner in which individuals conceptualize research approaches and their own identity. We have heard a number of early career professionals and colleagues claim to be a qualitative researcher or a quantitative researcher. It is our belief that much of this identification with a type of research has to do with the developmental stage of the scholar, the methodological leanings of their mentor(s), comfort or discomfort with particular approaches, and/or incomplete and inadequate research training. Developmentally speaking, it is important to remember that the researcher development process is long, intensive, and multi-stepped. Oftentimes, trainees leave a training program with a few research courses and a thorough capstone experience (e.g., thesis, dissertation) with one particular approach to research (e.g., survey research, case study). Naturally, it is normal to identify with the research approach one understands, however, it is important that trainees develop a foundational understanding that one approach is not the answer for all research problems/questions. While one might not know much during the formative years of research training, it is essential to have an understanding that research methodology and methods are tools within a belt of sorts, and depending on the research question/problem, a different tool can and should be used.

Most researchers have a mentor who was key in their development of competency in the research tradition they used to conduct their capstone research project. This mentor may have noticed a particular skillset the trainee brought to a research project. For example, competency and interest in statistics may have served as an antecedent for the mentor to encourage the trainee to conduct a quantitative investigation. Another possibility is the mentor encouraged the trainee to conduct research in an area in which the mentor has competency. While often not the intention of any party, this in-depth grounding in a particular research paradigm (i.e., mentoring) can have the unintended effect of creating camps. Instead of the aforementioned tool belt metaphor, early career professionals may start feeling they are only a quantitative or qualitative researcher. Furthermore, they can start to see the other types of research traditions as incompatible with their identity and capability as a researcher, or they may conceptualize their approach to research as being compatible with all research-based questions. To thwart these potential negative outcomes, trainees should be encouraged to engage in diverse trainings and experiences (e.g., research projects, thesis and dissertation, and case study reviews). Expanding one's repertoire would most likely have the result of increased self-efficacy in multiple approaches and viewing research methodology as the approach that best answers the research question or solves the research problem and not only one's personal interest (e.g., "I really like to provide in-depth interviews").

\section{Attaining Competence}

Can you imagine how absurd it would sound if someone said they were going to gain full competence as a cognitive behavioral therapist through reading one book chapter? To truly develop the therapeutic competency in any modality, a trainee would need formal education, required readings, years of practice, and frequent supervision. The same can be said for the attainment of research competency. No one piece of scholarship can provide trainees the necessary education, experience, 
and mentoring to thoroughly understand and efficiently execute a particular methodology. Reviewing a foundational graduate level research text can be a great starting place in terms of understanding a research tradition and, if written thoroughly, foundational readings can create a sense of awareness and understanding of the steps required to achieve research competency.

Prior to any formal education, it is important to remember that most early career professionals come to graduate school with research-based knowledge gained in previous courses and other educational and life experiences. Depending on the level of previous exposure, students will start to connect earlier knowledge to the new material being explored (Ambrose, Bridges, DiPietro, Lovett, \& Norman, 2010). In a general sense, the more connections one makes to the research world, the more research-based self-efficacy. The classroom is one place to enhance and foster growth within these research-based connections. Vygotsky (1978) described the classroom as a socially constructed environment that fosters collaboration through conversation and interaction with peers and instructors. Through the simultaneous learning of material and instructor-driven elaboration of particular, developmentally appropriate learning points, students are able to transfer theoretical and philosophical notions into pragmatic application in unique contexts. Similarly, Bain (2004) described how the best university instructors create effective learning experiences. One of his key areas was entitled structuring intentional learning experiences.

When instructing early career professionals in the area of research-based competency, it is helpful to intentionally scaffold deeper levels of review with hands-on application (e.g., team learning, case studies, and engaging in the research process). For example, upon entering a training program, a graduate student will take a foundational research course. During this course, there may be a variety of educational experiences. The experiences could be in the form of research-based discussions, case studies, exams, presentations, and/or peer critiques. Once a basic understanding of research has been achieved, students could collaborate with a faculty member or peer on the creation of a research project. This project would be supervised by a faculty member (required by most institutional review boards (IRBs), and would provide an initial opportunity to hone valuable research skills. Finally, most doctoral level programs have a capstone research experience (i.e., dissertation). Through the dissertation experience, students are mentored and supported in gaining in-depth researchbased competency. Through engaging in the research process and thoroughly being mentored in a methodology, one may begin to identify with a particular tradition (i.e., research identity).

Research competency is significantly increased when early career professionals experience initial success with scholarly tasks (Järvelä \& Renninger, 2014). Having a passionate and committed research mentor who is open to collaborating with early career professionals on initial research experiences is akin to having a knowledgeable tutor at one's service. When novice researchers witness their efforts culminating in the creation of new knowledge and a scholarly publication, the consequence is often an increase in research self-efficacy and a sense of motivation. The aforementioned motivation affects early career professionals because the research project reflects a combination of the high value the professional has placed on the project and their outcome expectancies regarding the research experience (Ambrose et al., 2010). Early mentoring and successful research experiences are often in the form of independent studies, collegial collaboration, mentor and mentee work, and turning one's dissertation or thesis into a refereed publication.

\section{HUMAN SUBJECTS RESEARCH}

Numerous ethical considerations surface when working with human research participants. As a community of scholars, we have learned a tremendous amount about the treatment of human 
participants from unethical and ethically questionable research studies (e.g., The Milgram Experiment, Stanford Prison Experiment). As researchers, we must consider how human subjects might be affected by the requirements of a study. Sheperis (2017) described 12 ethical areas where researchers can consider the implications for their work. These areas include: the research question, design of the study, methodology selected, data collection instruments, possible risks for participants, steps taken to minimize risks, data collection processes, presentation of informed consent, data analysis processes, confidentiality procedures, the processes in which results are shared (e.g., publications, discussions, presentations and workshops), and the researcher's decision to protect the participant's rights throughout the study (Sheperis, 2017).

When research involves human beings, certain ethical considerations must be taken into account. Throughout history, there have been numerous egregiously unethical experiments that have significantly impacted the lives of participants. Thankfully, the research community has made great strides toward ethical treatment of participants. The Belmont Report was the first official ethical code of conduct for researchers. Following the Belmont Report's ethical stipulations, the importance of informed consent was incorporated into the research community, and today it is an ethical requirement for researchers whom are members of the ACA, American Association for Marriage and Family Therapy (AAMFT), National Association of Social Workers (NASW), and APA to follow their codes of ethics.

\section{The Belmont Report}

The Tuskegee Syphilis Study generated a great deal of public outrage (Privitera, 2014), leading Congress to establish a National Commission for the Protection of Human Subjects in Biomedical and Behavioral Research in 1974, just 2 years after the study concluded (Privitera, 2014). The objective of the Commission was to identify and develop ethical guidelines for research involving human participation. In 1979, the Commission drafted and published the Belmont Report, which consisted of three principles for ethical research.

The three principles for ethical research, as determined by the Commission, are respect for others, beneficence, and justice (Wright, 2013). The principle of respect for others is comprised of two components: the moral obligation to respect and acknowledge autonomy, and to protect individuals who have decreased autonomy. Beneficence also had two elements; first to do no harm, and second to minimize all possible risk factors for the participants. The final principle of the Belmont Report, justice, stressed the importance and need to make certain that groups or classes of participants are going to benefit equally, as well as burdened equally, by the research project. For example, if conducting an experimental/control group research study on the efficacy of a mindfulness meditation group as an intervention to help manage anxiety, if the intervention proves successful, the same intervention must be given to the control group.

\section{Informed Consent}

Research participants should be viewed as volunteers and volunteers should enter into participation without coercion or improper reward for their participation (Wright, 2013). Participants, ethically, must clearly understand the risks of the study and understand their right to leave a study at any point. All of this information is covered in an informed consent agreement. The informed consent 
is a verbal and signed/confirmed process, where the description of the study, risks and rewards, confidentiality, compensation, and so forth are discussed and understood by the participant. The participant is informed to make a decision whether to participate in the study or not (Privitera, 2014). It is important to note that consent must be obtained prior to research starting and the informed consent does not relieve researchers from answering all of the participant's questions (Wright, 2013).

\section{HISTORY OF RESEARCH-BASED CONCERNS}

There have been numerous unethical studies performed throughout history, including (but not limited to) the Tuskegee Syphilis Study, Jewish Chronic Disease Hospital Cancer Cell Injections, Willowbrook Study, and Nazi Medical War Crimes (National Institutes of Health [NIH], 2002). As horrendous as these studies were, it is important to understand and reflect on the context, outcomes, procedures, and motivation behind these investigations. While focusing on the egregious ethical issues is important, it is also extremely helpful to consider why the policies, originating in the Belmont Report, were initially developed.

\section{Tuskegee Syphilis Study}

The Tuskegee Syphilis Study lasted a total of 40 years, beginning in 1932 and is one of the longest running studies to occur in the United States (Wester \& Hines, 2017). The intention of this study was to investigate the impact of syphilis in human beings and the researchers' sample consisted of 600 Black men, 399 infected with syphilis and 201 men without syphilis (Privitera, 2014). The participants were given misinformation and not given an informed consent. Participants were told they would be receiving treatment for "bad blood," although the men did not receive proper treatment.

Four years after the study began, the researchers understood that participants infected with syphilis had an increased number of, and more serious, complications than the non-infected population (Wester \& Hines, 2017). Despite this understanding the study continued. Ten years into the study, researchers observed that the risk of death doubled for participants with syphilis when compared to those without. Around the same time in the 1940s penicillin was acknowledged as an effective treatment for the disease, however participants were not notified or given treatment. This study continued for another 30 years after this, until a researcher expressed concern over the ethics of the study in 1968, leading to the study concluding in 1972 (Privitera, 2014).

\section{Jewish Chronic Disease Hospital Cancer Cell Injections}

In 1963, Dr. Chester Southam, at the Jewish Chronic Disease Hospital, was interested in researching if a healthy person could fight off cancer cells. This interest came from the idea that perhaps individuals suffering from cancer do not have enough antibodies and their bodies are unsuccessful in fighting off cancer cells due to another debilitation, therefore a human with an increased amount of antibodies was thought to be able to fight off the cancer cells. Southam and his team of researchers, at the Jewish Chronic Disease Hospital, were able to find participants for this study although they neglected to inform them what they would be injected with, nor were the participants provided an informed consent (Wester \& Hines, 2017). Later, Southam and his research team explained they did not feel it necessary to inform their participants of the risks involved with the study or tell them they were going to be injecting participants with cancer cells, as researchers feared this information 
could frighten potential participants. As a result of this study some patients did develop cancer. In an interview with the New York Post's Allen Hornblum, Southam was asked what would happen when the participants contracted the disease, to this Southam answered "If they did, we'd just cut it out" (Hornblum, 2013).

\section{Willowbrook Study}

The Willowbrook Study took place in a significantly overcrowded and understaffed school on Staten Island, New York, in 1963 (Wright, 2013). The researchers infected healthy children with intellectual disabilities with the live hepatitis virus. Some were infected orally, while others were injected with the virus (Wright, 2013). Parents were coerced into consenting to this treatment by the Willowbrook State School. Officials from the school stated that the children would only be admitted if they took part in the study. They added that even if a child were not to participate in the study, the child would still be infected with the virus simply from being at the school, due to the overcrowding and general lack of cleanliness (Wester \& Hines, 2017). As a result of this research, many children became very ill. This study went on for 14 years, and ultimately, some children were treated while others were not.

\section{Nazi Medical War Crimes}

In concentration camps, Nazi physicians preformed numerous studies on their prisoners during World War II (Wester \& Hines, 2017). The treatment the prisoners received during this time include injections with gasoline and live viruses. In addition to these injections, many prisoners were immersed in ice water or were forced to consume poison. Unsurprisingly, these studies often resulted in the death of the prisoner or in disease and suffering. The Nazi party was eventually tried and convicted for crimes against humanity due to the monstrosities that occurred in the concentration camps.

\section{INSTITUTIONAL REVIEW BOARDS AND FEDERAL GUIDELINES}

With the same intention of the Belmont Report's three principles-respect for others, beneficence, and justice-the IRB was created. IRBs are organizations with a minimum of five members (e.g., scientist, non-scientist, prisoner advocate, chairperson, and a member who is not otherwise affiliated with the institution), one of which must come from outside the institution (Privitera, 2014). All institutions receiving federal funding have an IRB, including universities, schools, hospitals, and some community agencies (Wester \& Hines, 2017). The IRB's purpose is to review the protocols of research, weigh the risks and benefits of the research, and determine the level of risk involved; no risk, minimal risk, or greater-than-minimal risk.

In addition to the aforementioned IRB guidelines, there are federal regulations that must be upheld as well. Federal regulations for research with human participants, 45 CFR part 46, is broken into four subparts (Office of Human Research Protections, 2016). Subpart A defines federal policies for working with human participants, this is also called the common rule. Subpart B describes the additional protections needed for research involving pregnant women, fetuses, and neonates. Subpart $\mathrm{C}$ clarifies the additional protections required for prisoners. Lastly, Subpart D explains additional protection required when working with children. Information about the federal regulations and 
the Electronic Code of Federal Regulations can be found on the Department of Health and Human Services website at https://www.hhs.gov/ohrp/regulations-and-policy/regulations/common-rule/ index.html. All emerging and seasoned researchers should review these guidelines regularly.

\section{MULTICULTURAL ISSUES}

Minority populations, low income populations, confined populations, and women who are single or pregnant are considered to be more vulnerable to unethical research practices (Wester \& Hines, 2017). Given this information, it is important to assess, as the researcher, one's own understanding of work with multicultural populations. Investigators must continually remain culturally competent throughout the entire research process. Wester and Hines (2017) describe three competencies, recognized by the ACA, which guide researchers in their work with multicultural backgrounds.

The first competency requires the investigator to be aware of their own values and biases. For example, if a researcher is a happily married woman and she is doing research on the effectiveness of an intervention for married couples considering divorce, she may strongly value marriage and have negative thoughts about divorce, which could set the stage for her being biased toward the efficacy of the intervention and the research in general. The second competency states that researchers must have an understanding of the participants' world view. It is important for researchers to acknowledge that everyone has a unique world view. Thus, researchers must gain some understanding of the lens from which their participants view the world (e.g., demographic questionnaire, reflective journal, processing probes). Lastly, the third competency requires that interventions be appropriate with the understanding gained from the prior two competencies. For example, it is very important for researchers not to generalize their findings to unexplored populations. If an intervention has proven effective for homeless African American women, this does not mean researchers can assume it will be successful for homeless Mexican American women.

\section{SUMMARY}

Throughout this chapter you were introduced to the philosophical and pragmatic aspects of research traditions, research ethics, and information on the importance of scholarly rigor and identity. As you continue your journey through the remainder of this textbook, you will review the way specific research traditions use the general concepts and topics discussed in Chapter 1. Specifically, the contributing authors will review each tradition's philosophical integration, rigor, and history. Given that the nature of this textbook is centered on future producers of research, it is our hope that information presented within each chapter will create a sense of motivation to start initiating research projects and self-efficacy in understanding the essence of research. Through reading this chapter, you learned the basic blueprints of qualitative, quantitative, and mixed methods research. Good luck in your future work as researchers, we hope you will contribute, in your own way, to our shared intellectual community.

\section{STUDENT ACTIVITIES}

\section{Exercise 1: The Scientific Method}

Directions: Consider the scientific method described herein. The scientific method is a standardized way of gathering data, testing predictions, and interpreting results. Conduct an Internet search 
on the terms replicability, precision, falsifiability, and parsimony as they relate to the scientific method. Following this search answer the following questions.

What is Ockham's razor and how does it relate to parsimony?

- Review the following link and describe how the work of Karl Popper impacted the notion of falsification. https://plato.stanford.edu/entries/popper/

- Given the information you just learned on the scientific method, how can one know something scientifically? How is this knowledge best obtained?

\section{Exercise 2: Writing a Research Question}

Directions: Review all of the variations and example research questions herein. Consider research problems/topics that are of interest to you. Practice writing your own research question for each of these different variations of research questions.

\section{Exercise 3: Developing a Tradition-Based Purpose Statement}

Directions: Review the following qualitative, quantitative, and mixed methods purpose statement frameworks. Creatively, fill in the blanks with the appropriate nomenclature.

\section{Qualitative Purpose Statement}

The purpose of the present study was to (explore, uncover, etc.) how

(counselors, psychologists, etc.) can help in the (construct being explored) of (particular participants being explored) and to propose a

(grounded theory, phenomenon, etc.) of the (name of the construct being explored) of (particular demographic being explored).

\section{Quantitative Purpose Statement}

The purpose of this investigation was to test by comparing (group 1) and intervention (independent variable) (dependent variable) for (participants) at (group 2) in terms of the (research site)

\section{Mixed Methods Purpose Statement}

The purpose of this mixed methods study was to explore the use of (construct of interest) with (participants of interest) to enhance their understanding of the predicting relationship between (independent variable) and (dependent variable), via mixed methods analysis.

\section{Exercise 4: Gaining Research Expertise}

Directions: Gaining competence in a research design is no simple task, however it is something that is achievable. Respond to the following prompts: Describe one methodological framework that is interesting to you. Where can you find a mentor in this area (e.g., faculty at your university, professor at a different institution, book author, etc.)? Reach out to this individual and ask them 
if you could consult with them and/or collaborate with them on a project. Review the scholarly literature and find two books or articles describing your methodology of interest. Now you are starting your scholarly journey in gaining research competence.

\section{Exercise 5: Writing the Informed Consent}

Directions: Go to your university's IRB website. Find the requirements for the informed consent document. Now consider a research study that you would like to conduct during your time in graduate school. Complete the entire informed consent document based on your research interest.

\section{ADDITIONAL RESOURCES}

\section{Software Recommendations}

NVivo Software (https://www.qsrinternational.com)

CAQDAS Software (https://www.maxqda.com)

ATLAS ti (https://atlasti.com)

MaxQDA (https://maxda.com)

Statistical Package for the Social Sciences (SPSS): (https://www.ibm.com/analytics/spss-statisticssoftware)

R: (https://www.r-project.org/)

SAS: (https://www.sas.com/en_us/software/stat.html)

Mplus: (https://www.statmodel.com/)

\section{Helpful Links}

nttps://www.ecfr.gov/cgi-bin/retrieveECFR?gp $=\& S I D=83 c d 09 e 1 c 0 f 5 c-$ $6937 \mathrm{~cd} 9 \mathrm{~d} 7513160 \mathrm{fc} 3 \mathrm{f} \& \mathrm{pitd}=20180719 \& \mathrm{n}=\mathrm{pt} 45.1 .46 \& \mathrm{r}=$ PART $\& \mathrm{ty}=\mathrm{HTML}$

n https://people.uwec.edu/piercech/ResearchMethods/Data\%20collection\%20methods/ DATA\%20COLLECTION\%20METHODS.htm

- https://towardsdatascience.com/sampling-techniques-a4e34111d808

- https://www.healthknowledge.org.uk/public-health-textbook/research-methods/1aepidemiology/methods-of-sampling-population

- https://www.wikihow.com/Understand-and-Use-Basic-Statistics

- https://www.statisticshowto.datasciencecentral.com/reliability-validity-definitionsexamples/

- https://nursekey.com/trustworthiness-and-integrity-in-qualitative-research/

- https://cirt.gcu.edu/research/developmentresources/research_ready/mixed_methods/ choosing_design

\section{Helpful Books}

Audi, R. (2010). Epistemology: A contemporary introduction to the theory of knowledge (3rd ed.). Routledge. Creswell, J. W. (2017). Research design: Qualitative, quantitative, and mixed methods approaches (5th ed.). SAGE. 
Crotty, M. (2003). The foundations of social research: Meaning and perspective in the research process (2nd ed.). SAGE.

Effingham, N. (2013). An introduction to ontology. Polity Press.

Hays, D. G., \& Singh, A. A. (2012). Qualitative inquiry in clinical and educational settings. Guilford.

Hurlburt, R. T. (2017). Comprehending behavioral statistics (6th ed.). Kendall Hunt.

Lincoln, Y. S., \& Guba, E. G. (1985). Naturalistic inquiry. SAGE.

Meltzoff, J., \& Cooper, H. (2018). Critical thinking about research: Psychology and related fields (2nd ed.). American Psychological Association.

Sheperis, C. J., Young, J. S., \& Daniels, M. H. (2017). Counseling research: Quantitative, qualitative, and mixed methods. Pearson.

\section{Helpful Videos}

nttps://www.khanacademy.org/math/cc-sixth-grade-math/cc-6th-data-statistics/ cc-6-statistical-questions/v/understanding-statistical-questions

- https://www.youtube.com/watch?v=wbdN_sLW188

nttps://www.youtube.com/watch?v=IsAUNs-IoSQ

- https://www.youtube.com/watch?v=JHNNNW97ssI

\section{KEY REFERENCES}

Only key references appear in the print edition. The full reference list appears in the digital product found on http://connect.springerpub.com/content/book/978-0-8261-4385-3/part/part01/chapter/ch01

Alderman, N., \& Knight, C. (2017). Keeping the "scientist-practitioner" model alive and kicking through service-based evaluation and research: Examples from neurobehavioural rehabilitation. The Neuropsychologist, 3, 25-31.

Audi, R. (2010). Epistemology: A contemporary introduction to the theory of knowledge (3rd Ed.). Routledge. Babbie, E., \& Mouton, J. (2010). The practice of social research (10th ed.). Oxford University Press.

Biesta, G. (2010). Pragmatism and the philosophical foundations of mixed methods research. In A. Tashakkori \& C. Teddlie (Eds.), SAGE handbook of mixed methods in social and behavioral research (2nd ed., pp. 95-118). SAGE.

Bhattacherjee, A. (2012). Social science research: Principles, methods, and practices. Textbooks Collection. Book 3.

Creswell, J., \& Plano Clark, V. (2017). Designing and conducting mixed methods research (3rd ed.). SAGE. Crotty, M. (2003). The foundations of social research: Meaning and perspective in the research process. SAGE. Flynn, S. V., \& Korcuska, J. S. (2018a). Credible phenomenological research: A mixed methods study. Counselor Education \& Supervision, 57, 34-50. doi:10.1002/ceas.12092

Flynn, S. V., \& Korcuska, J. S. (2018b). Grounded theory research design: An investigation into practices and procedures. Counseling Outcome Research and Evaluation, 9, 102-116. doi:10.1080/21501378.20 17.1403849

Flynn, S. V., Korcuska, J. S., Brady, N. V., \& Hays, D. G. (2019). A 15-year content analysis of three qualitative research traditions. Counselor Education \& Supervision, 58, 49-63. doi:10.1002/ceas.12123

Hays, D. G., \& Singh, A. A. (2012). Qualitative inquiry in clinical and educational settings. Guilford.

Office of Human Research Protections. (2016). Federal policy for the protection of human subjects ("Common Rule"). Retrieved July 6, 2019, from https://www.hhs.gov/ohrp/regulations-and-policy/ regulations/common-rule/index.html

Onwuegbuzie, A. J., \& Johnson, R. B. (2006). The validity issue in mixed research. Research in the Schools, $13,48-63$.

Scotland, J. (2012). Exploring the philosophical underpinnings of research: Relating ontology and epistemology to the methodology and methods of the scientific, interpretive, and critical research paradigms. English Language Teaching, 5(9), 9-16. doi:10.5539/elt.v5n9p9 